DUCE, Mauricio. "El derecho a confrontación y uso de declaraciones emitidas en un juicio previo anulado".

Polít. crim. Vol. 9, № 17 (Julio 2014), Art. 4, pp. 118-146.

[http://www.politicacriminal.cl/Vol_09/n_17/Vol9N17A4.pdf]

\title{
Derecho a confrontación y uso de declaraciones emitidas en un juicio previo anulado.
}

\author{
Mauricio Duce J. \\ Magíster en Ciencias Jurídicas Universidad de Stanford \\ Profesor Titular Facultad de Derecho Universidad Diego Portales \\ mauricio.duce@udp.cl
}

\section{Resumen}

El propósito del artículo es aportar al conocimiento doctrinario y desarrollo jurisprudencial de nuestro país por medio de la presentación de información y elaboración de argumentos para resolver un problema específico que se ha debatido intensamente en la práctica de tribunales: la posibilidad de permitirle o no al acusado (su defensa) -en virtud al artículo 332 del Código Procesal Penal- utilizar las declaraciones prestadas por testigos y peritos en un juicio oral previo anulado en el contexto del desarrollo del nuevo juicio oral que se ha seguido como consecuencia de la anulación del primero. Sostendré que no existen buenas razones legales ni de principios o de valores que inspiran a nuestro sistema acusatorio que justifiquen la prohibición absoluta de utilizar estas declaraciones para efectos de confrontar a esos testigos o peritos con sus declaraciones previas inconsistentes. Para estos efectos, el artículo fijará un marco conceptual para debatir el problema (ubicarlo como una cuestión de derecho de confrontación y, especialmente, de derecho a contraexaminar) y luego se detendrá en la elaboración de argumentos en favor de su uso y en la revisión crítica de los argumentos que usualmente se invocan en su contra.

Palabras clave: Derecho de confrontación, contraexamen, uso de declaraciones previas inconsistentes.

\begin{abstract}
The goal of this paper is to make a contribution for scholarly knowledge and jurisprudential development of our country through the presentation of information and the elaboration of arguments to resolve a specific problem that has been highly debated before Chilean courts: the possibility to allow or to deny the defendant (or her lawyer) -according to article 332 of the Criminal Procedural Code- the use of statements made by witnesses and expert witnesses in a trial that was annulled in the new trial that is the consequence of the first one. I will argue that there are no good legal reasons nor of principles and values that inspire our adversarial system that justify an absolute prohibition to use these statements with the goal to confront those witnesses and expert witnesses with their prior inconsistent statements. To achieve this, the paper will propose a conceptual framework to understand the problem (right to confront witnesses and particularly right to cross-examine) and then will elaborate arguments in favor of this position and critically review the arguments against it.
\end{abstract}

Key words: Right to confront witnesses, cross-examination, use of prior inconsistent statements. 
DUCE, Mauricio. "El derecho a confrontación y uso de declaraciones emitidas en un juicio previo anulado".

\section{Introducción $^{1}$}

El sistema procesal penal de corte acusatorio vigente en nuestro país desde el año 2.000 ha introducido cambios muy significativos en el diseño y lógica del proceso penal con un enorme impacto en la forma de comprender los alcances y contenidos de las diversas garantías que integran al debido proceso penal. Se trata de un cambio "cultural" muy profundo que poco a poco se ha ido reflejando en las decisiones de distintos tribunales sobre materias que, por el diseño del sistema inquisitivo anterior, no habían tenido espacio para su desarrollo por la doctrina y la jurisprudencia nacional. El cambio procesal ha obligado a los tribunales a enfrentar situaciones nuevas que les han exigido ampliar los marcos tradicionales bajo los cuales las garantías en juego habían sido analizadas previamente en nuestro país, lo cual ha significado una expansión muy relevante de las mismas y un desarrollo jurisprudencial creciente. ${ }^{2}$

Un derecho donde naturalmente se ha producido esta evolución es en materia de derecho de confrontación o, como ha sido tratado habitualmente en la doctrina nacional, el derecho o principio de contradictoriedad. ${ }^{3}$ Así, uno de los aspectos de este derecho en el que se ha venido planteando una discusión importante a nivel de tribunales en los últimos años, lamentablemente con menos claridad de la necesaria, ha sido el referido a la posibilidad de permitirle o no al acusado (su defensa) -en virtud al artículo 332 del CPP- utilizar las declaraciones prestadas por testigos y peritos en un juicio oral previo anulado en el contexto del desarrollo del nuevo juicio oral que se ha seguido como consecuencia de la anulación del primero.

A pesar de la importancia práctica que tiene la resolución de este tema para el funcionamiento adecuado del sistema, se trata de un problema cuyo desarrollo doctrinal ha

\footnotetext{
${ }^{1}$ El presente trabajo se ha estructurado sobre la base de un informe en derecho que el autor elaboró y que fue solicitado por el Estudio Jurídico "Balmaceda y Cox Abogados" en la causa por recurso de nulidad seguido ante la Corte Suprema rol n $\mathrm{n}^{\mathrm{0}}$ 2866-2012 (fallado el 17 de junio de 2013). El texto fue entregado en el mes de abril de 2013. Agradezco especialmente al abogado Francisco Cox la autorización para utilizar los contenidos de dicho informe para construir este artículo. En todo caso, cabe mencionar que esta versión contiene cambios importantes en la estructura y contenidos del texto original, agregando, entre otras cosas, temas y nuevas fuentes no consideradas previamente, como a su vez eliminando partes que no eran pertinentes para este texto. ${ }^{2}$ Un buen ejemplo que da cuenta del punto es el debate que sobre el alcance de la garantía de imparcialidad ha existido a propósito de la facultad de los jueces para realizar en juicio preguntas aclaratorias de testigos y peritos de conformidad al artículo 329 inciso 4 del Código Procesal Penal (en adelante el "CPP"). Allí en donde en el contexto del sistema inquisitivo nuestra doctrina y jurisprudencia convivió pacíficamente con una situación extrema como lo era que un mismo juez que no sólo investigaba y acusada sino también fallaba el caso, en el sistema acusatorio se ha llegado a consolidar una doctrina jurisprudencial que entiende que jueces que ejercen muy activamente la facultad del artículo mencionado comprometerían la garantía de imparcialidad y se ha dado lugar a nulidad de juicio respectivo. Como puede apreciarse, realmente existe un mundo de diferencia en cuanto a la comprensión y alcances de la garantía en estos dos escenarios procesales. Un análisis sobre el problema y parte de la jurisprudencia en este punto puede verse en ROJAS, Julio, "El rol del juez en la prueba: efectos que genera en el juicio oral la formulación de preguntas aclaratorias a testigos y peritos conforme al artículo 329 inciso cuarto del Código Procesal Penal," en: VV.AA, Diez años de la reforma procesal penal en Chile, Santiago: Ediciones Universidad Diego Portales, 2011, pp. 432-456.

${ }^{3}$ Me referiré más adelante a esta diferencia de nomenclatura. Véase infra 1.1.
} 
Polít. crim. Vol. 9, № 17 (Julio 2014), Art. 4, pp. 118-146.

[http://www.politicacriminal.cl/Vol_09/n_17/Vol9N17A4.pdf]

sido escaso. ${ }^{4}$ Esto se ha traducido en una jurisprudencia bastante confusa y que, por regla general, no se haya abordado la cuestión utilizando un marco conceptual adecuado.

La tendencia jurisprudencial aparentemente mayoritaria hasta el mes de junio de 2013 había sido entender que no era posible utilizar declaraciones de un juicio previo anulado debido a que los efectos del recurso de nulidad producirían una suerte de inexistencia de todo el material producido en el juicio anulado. En consecuencia, con la anulación del juicio se produciría una inexistencia jurídica de todo lo ocurrido en el mismo que también lleva aparejada una inexistencia fáctica. ${ }^{5}$ Este criterio ha sido cambiado por la Corte Suprema en una decisión de junio de 2013 que ha sostenido que el no permitir utilizar las declaraciones previas de un juicio anulado de testigos (las víctimas) y un perito producen una infracción al debido proceso que se traduce en la nulidad de la sentencia y el juicio oral en virtud de la causal del artículo 373 letra a) del CPP. ${ }^{6}$ Esta decisión representa, en mi opinión, un enorme avance para resolver adecuadamente el problema. Con todo, como ha sido demostrado por la investigación disponible en la materia, una decisión de la Corte Suprema no garantiza necesariamente la unificación de la jurisprudencia en nuestro país. ${ }^{7}$ Por otra parte, si bien la decisión de la Corte parece apuntar en la dirección correcta, estimo no se hace cargo de todos los aspectos de fondo que debieran considerarse para consolidar una doctrina jurisprudencial clara en la materia. Se trata de una cuestión que, en mi opinión, sólo se puede resolver correctamente con una adecuada comprensión del derecho a confrontación que ha sido poco tratado por nuestra doctrina y jurisprudencia.

En este contexto, el propósito del presente trabajo es aportar al conocimiento doctrinario y desarrollo jurisprudencial de nuestro país mediante una caracterización del derecho a confrontación que en general no ha estado presente en nuestra literatura y la elaboración y perfeccionamiento de argumentos para justificar el uso de declaraciones vertidas en juicios anulados como forma de contrastar declaraciones en virtud del uso del artículo 332 del CPP. Como se puede anticipar, estimo que la negativa de permitirle utilizar al acusado estas declaraciones generaría una infracción al debido proceso. Como se trata de un problema

\footnotetext{
${ }^{4}$ El único trabajo académico que se refiere específicamente a este problema es el de VIAL, Pelayo "El derecho a confrontación con declaraciones de un juicio anulado en el marco del proceso penal", Polít. crim. Vol. 6, $\mathrm{N}^{\mathrm{o}} 12$ (diciembre 2011). Art. 6, pp. 448-473, en: www.politicacriminal.cl/Vol_06/n_12/Vol6N12A6.pdf (última visita el 6 de enero de 2014). El autor sostiene que las declaraciones previas de testigos en un juicio anulado sí podrían ser utilizadas para el propósito de manifestar contradicciones o inconsistencias en el juicio nuevo. Se trata de un buen trabajo de investigación que aporta muchos elementos para resolver el tema en análisis y que utilizaré en este trabajo, pero que tampoco se hace cargo de todas las dimensiones del problema en nuestra legislación procesal penal y, en todo caso, es previo a la decisión en que la Corte Suprema cambió su línea jurisprudencial en la materia.

${ }^{5}$ Por ejemplo véase sentencia de la Corte Suprema en causa rol no $5417-2007$ de 24 de diciembre de 2007 (citada por VIAL, "El Derecho a confrontación", cit. nota $n^{\circ} 4$, p. 449).

${ }^{6}$ Véase sentencia de la Corte Suprema en causa rol no 286-2012 de 17 de junio de 2013.

7 COUSO, Jaime; MERA, Jorge. Precedentes y justicia penal, Santiago: Ediciones Universidad Diego Portales, 2011, especialmente ver capítulo III, pp. 199-232. Como producto de una investigación de líneas jurisprudenciales de tribunales superiores y diversas entrevistas a magistrados que los integran los autores concluyen que en nuestra judicatura existe una convicción generalizada que la jurisprudencia de la Corte Suprema no es vinculante y que ello es, incluso, un fenómeno positivo. En este contexto es fácil concluir que una sola decisión en un tema que hasta el momento ha sido polémico no necesariamente va a ser capaz de cambiar las prácticas a nivel de tribunales inferiores.
} 
DUCE, Mauricio. "El derecho a confrontación y uso de declaraciones emitidas en un juicio previo anulado".

que no contiene una solución explícita en nuestro CPP, ello obliga a justificar esta postura recurriendo a una reflexión acerca de los valores que se ponen en juego y una interpretación de nuestra legislación procesal penal basada en esos valores y no en cuestiones formales. También se hace necesario recurrir al derecho internacional de los derechos humanos y al derecho comparado, especialmente la experiencia de países que cuentan con sistemas acusatorios más desarrollados y que han servido de inspiración para el desarrollo de nuestro actual modelo procesal penal.

Mi opinión es que no existen buenas razones legales ni de principios o de valores que inspiran a nuestro sistema acusatorio que justifiquen la prohibición absoluta de utilizar las declaraciones prestadas por testigos o peritos en un juicio oral previo para efectos de confrontar (manifestar inconsistencias, mostrar contradicciones) con las declaraciones prestadas por estos mismos en el nuevo juicio oral. Por el contrario, una práctica en esta dirección pone en juego seriamente uno de los objetivos centrales del sistema probatorio como lo es el de constituir una instancia que permita testear intensamente la calidad de la información que contribuya a que el tribunal tome una decisión también de alta calidad (sin errores). Además, cuando dicha práctica juega en contra del acusado y, a través de ella, se le impide manifestar contradicciones o inconsistencias de relevancia para poder valorar la credibilidad y calidad de los testigos y peritos, ello afecta al derecho a confrontación (en su dimensión del derecho a contrainterrogar) ampliamente reconocido por el derecho internacional de los derechos humanos, el derecho comparado y por nuestra legislación.

A la luz del objetivo planteado el presente trabajo se organiza en tres secciones. En la primera revisaré brevemente los alcances y consagración normativa del derecho a confrontación, con énfasis específico en el derecho a interrogar a los testigos adversos como elemento integrante del mismo. En la segunda sección analizaré el rol que cumple el uso de las declaraciones previas para asegurar el derecho a contraexaminar y, en particular, como nuestro CPP ha regulado la posibilidad de utilizar estas declaraciones como un componente básico para el ejercicio adecuado del derecho a contraexaminar. En la tercera sección, me haré cargo de las principales objeciones que podrían realizarse a la tesis planteada demostrando que no constituyen buenas razones para impedir el uso de las declaraciones provenientes de un juicio anulado para efectos del artículo 332 del CPP. Concluiré el trabajo con unas breves reflexiones finales.

\section{El derecho a confrontación y el contraexamen.}

Un primer paso para comprender bien el problema y la postura que he manifestado supone revisar brevemente el derecho fundamental que se vería afectado con la no autorización del uso de declaraciones previas del juicio anulado. Para ello revisaré la consagración y alcances generales del derecho a confrontación y, luego, del derecho al contrainterrogatorio o contraexamen en particular. ${ }^{8}$

\footnotetext{
${ }^{8}$ Para los efectos de este trabajo utilizaré las expresiones "contrainterrogatorio" y "contraexamen" como sinónimas.
} 
Polít. crim. Vol. 9, № 17 (Julio 2014), Art. 4, pp. 118-146.

[http://www.politicacriminal.cl/Vol_09/n_17/Vol9N17A4.pdf]

\subsection{El derecho a confrontación y su reconocimiento jurídico:}

El derecho a confrontación de los testigos y peritos es considerado como un elemento central del debido proceso en los sistemas procesales contemporáneos. ${ }^{9}$ Es, además, una de las principales manifestaciones del derecho a defensa de los acusados. Por lo mismo, se trata de una garantía fundamental ampliamente reconocida en la legislación internacional, el ámbito comparado y nuestro sistema jurídico.

Así, el artículo 6.3 del Convenio Europeo de Derechos Humanos (en adelante, el "CE") establece que el acusado de un delito tiene derecho a "...interrogar o hacer interrogar a testigos que declaren en contra de él..." La Corte Europea de Derechos Humanos ${ }^{10}$ y la doctrina $^{11}$ que la analiza, han destacado en forma reiterada que se trata de una garantía que constituye un componente mínimo del derecho a un juicio justo (debido proceso). ${ }^{12}$ De una manera similar, el artículo 14.3 letra e) del Pacto Internacional de Derechos Civiles y Políticos ${ }^{13}$ (en adelante, el "Pacto") establece que toda persona acusada de un delito tiene derecho a "...interrogar y hacer interrogar los testigos de cargo...", lo que también ha sido comprendido como un elemento esencial de la noción de debido proceso. ${ }^{14}$ Por su parte, la Convención Americana de Derechos Humanos (en adelante, la "CA") ${ }^{15}$ regula en su artículo 8.2 letra f) el derecho de las personas acusadas "... de interrogar a los testigos presentes en el tribunal...", regla que también ha sido comprendida como una piedra angular del debido proceso penal. ${ }^{16}$

Como se puede apreciar, más allá de los matices de las distintas regulaciones, todas ellas establecen un derecho bastante fuerte en favor de los acusados por un delito. Este derecho consiste en que el acusado debe contar con una oportunidad para interrogar o examinar a los testigos o peritos que aportarán información que los perjudica.

El núcleo central de este derecho consiste, entonces, en entregarle la posibilidad al acusado de controvertir intensamente la información aportada por testigos (y peritos) adversos en juicio. Entendido así, este derecho cumple al menos dos funciones. Por una parte, asegura

\footnotetext{
${ }^{9}$ SUMMERS, Sarah, Fair trials: The European criminal procedural tradition and the European court on human rights, Oxford: Hart Publishing, 2007, pp. 146-148.

${ }^{10}$ Por ejemplo véase Sentencia de 10 de febrero de 2006 caso Bocos-Cuesta v. The Netherlands, párrafo 56.

11 TRECHSEL, Stefan, Human rights in criminal proceedings, New York: Oxford University Press, 2006, p. 292.

${ }^{12}$ Desde ya vale la pena aclarar que a pesar que la redacción de esta norma pone acento en la idea de "testigos", se ha entendido unánimemente que ello abarca no sólo a los "testigos" en sentido más estricto sino que también a peritos y a las partes que declaran en juicio. Sobre el punto véase TRECHSEL, Human rights, cit. nota $\mathrm{n}^{\mathrm{o}} 11$, pp. 302-304.

${ }^{13}$ Es necesario recordar que el Pacto ha sido ratificado por Chile e incorporado a la legislación interna mediante su publicación en el Diario Oficial el día 29 de abril de 1989.

${ }^{14}$ NOWAK, Manfred, U.N Covenant on Civil and Political Rights CCPR Commentary, Germany: N.P Engel Publisher, 2005, pp. 34; McGOLDRICK, Dominic, The Human Rights Committee, Oxford. Clarendon Press, 1996, p. 405.

${ }^{15}$ Se trata de un instrumento que también ha sido incorporado a la legislación interna por medio de su publicación en el Diario Oficial el 5 de enero de 1991.

${ }^{16}$ En esta dirección se puede ver Sentencia de la Corte Interamericana de Derechos Humanos de 22 de noviembre de 2005, Caso Palamara vs. Chile, párrafo 178.
} 
DUCE, Mauricio. "El derecho a confrontación y uso de declaraciones emitidas en un juicio previo anulado".

que el acusado tenga una participación activa en el caso y pueda influir en el proceso de formación de convicción del tribunal que debe resolver. Dicho en otros términos, que la decisión del tribunal respecto a la prueba presentada considere los puntos de vista y antecedentes aportados por el acusado. ${ }^{17}$ Por la otra, constituye un aspecto central para asegurar una decisión de mejor calidad del juzgador toda vez que la información aportada en el interrogatorio del acusado permitirá contar con más antecedentes y mejorar la evaluación de credibilidad del testigo (o perito), favoreciendo una decisión judicial basada en información de mayor calidad. ${ }^{18}$ En esta segunda dimensión, el derecho a confrontación juega un rol institucional significativo ya que será un mecanismo que asegure al sistema el cumplimiento adecuado de su deber de establecer verdad y resolver las controversias conforme a ella. Por lo mismo, la infracción de este derecho no sólo perjudica al acusado sino que a la sociedad en su conjunto ya que deteriora las condiciones de producción de la prueba que minimizan la posibilidad de error en la decisión judicial.

Según reporta Trechsel, el origen de la cláusula que regula al derecho de confrontación en el sistema internacional de protección de derechos humanos estaría en la propuesta formulada por los Estados Unidos al artículo 11 de la Declaración Universal de Derechos Humanos, lo que mostraría se trata de un derecho que cuenta con fuertes raíces en la tradición anglosajona de procedimiento penal. ${ }^{19}$ En efecto, en las ideas que he expresado se encontrarían detrás de este derecho se pueden percibir una clara concepción acusatoria o adversarial del proceso. Por lo mismo, en su estudio y comprensión es importante conocer el desarrollo que ha tenido esta garantía en dichos países. En esta dirección, resulta de particular interés señalar que se trata de un derecho con larga tradición en los Estados Unidos, habiéndose recogido de manera explícita en la enmienda sexta de su Constitución que establece "The accused shall enjoy the right to be confronted with the witnesses against him". ${ }^{20}$ Se puede apreciar un contenido muy similar al expresado por los tratados internacionales ya revisados.

En la actualidad, se trata de un derecho que se ha expandido con fuerza en todas las tradiciones procesales lo que hace que tenga un estatus más bien universal como lo demuestra su consagración en los tratados internacionales de derechos humanos. Esto ha llevado a que se trate de una garantía que suele ser objeto de reconocimiento explícito en los sistemas constitucionales contemporáneos. Así, normas muy parecidas a la transcrita se repiten en las constituciones de varios países de la tradición jurídica del Common Law y del

\footnotetext{
${ }^{17}$ Desde este punto de vista se suele asociar a este derecho con el derecho de defensa y la "igualdad de armas". En este sentido véase Comité de Derechos Humanos, Observación General no 32, 2007, párrafo 39. En el contexto del sistema del Convenio Europeo véase VAN DIJK, Pieter; VAN HOOF, Fried; VAN RIJN, Arjen; ZWAAK, Leo (eds.), Teoría y práctica del convenio europeo de derechos humanos, Colombia: Universidad Los Andes, 2009, p. 431; OVEY, Claire; WHITE, Robin, The European Convention on Human Rights, Oxford: Oxford University Press, 2006, p. 207.

${ }^{18}$ Esta dimensión ha estado particularmente presente en la tradición anglosajona. Así en los Estados Unidos ha existido un consenso bastante fuerte en la jurisprudencia y doctrina por considerar que el derecho a contraexaminar constituye la herramienta procesal más efectiva para el establecimiento de la verdad en el proceso. Entre otros, véase, FONTHAM, Michael, Trial technique and evidence, Estados Unidos: National Institute for Trial Advocacy, 2008, p. 409.

${ }^{19}$ TRECHSEL, Human rights, cit. nota ${ }^{\circ} 11$, p. 292.

${ }^{20}$ En castellano la traducción sería "El acusado gozará del derecho a confrontar a los testigos en contra suya" (traducción del autor).
} 
Polít. crim. Vol. 9, № 17 (Julio 2014), Art. 4, pp. 118-146.

[http://www.politicacriminal.cl/Vol_09/n_17/Vol9N17A4.pdf]

ámbito europeo continental. Un par de ejemplos dan cuenta de esta regulación. En el mundo europeo continental puede verse el artículo 111 inciso segundo de la Constitución de Italia que señala, en la parte respectiva, que "Durante el juicio penal la ley garantizará que la persona acusada de un delito... tenga la facultad, ante el juez, de interrogar o hacer que se interrogue a aquellas personas que declaran en contra de él..."21 En el ámbito de Latinoamérica un ejemplo puede verse en lo regulado por el artículo 29 inciso cuarto de la Constitución de Colombia que señala en su parte pertinente que "Quien sea sindicado tiene derecho a la defensa y .... a presentar pruebas y a controvertir las que se alleguen en su contra..."22

Nuestro país no se ha queda atrás en el reconocimiento de este componente del debido proceso, aún cuando no lo haya hecho de manera tan directa o explícita como en los ejemplos anteriores. En primer lugar, se debe entender incorporado a nuestra legislación interna en virtud de la norma del inciso segundo del artículo 5 de nuestra Constitución que establece como límite al ejercicio de la soberanía los derechos fundamentales garantizados por los tratados internacionales ratificados y vigentes. A ello se suma la cláusula del artículo $19 \mathrm{n}^{\mathrm{o}} 3$ inciso sexto que establece el reconocimiento a las garantías que integran a un procedimiento e investigaciones racionales y justos. Existe amplio consenso doctrinal y jurisprudencial respecto a que esta cláusula regula al debido proceso en nuestro ordenamiento constitucional $^{23} \mathrm{y}$, en consecuencia, debiera incluir a una de sus garantías básicas como el derecho a confrontación. Así, por lo demás, lo ha señalado en forma explícita la jurisprudencia de nuestra Corte Suprema al incorporarla en el listado de las garantías que integrarían al debido proceso. Por ejemplo, en el caso de junio de 2013 que ya he citado la Corte señaló que la garantía del debido proceso, regulada en el artículo 19 no 3 inciso sexto de la Constitución, incluye entre otros "(4) el derecho a presentar pruebas de descargo y examinar la prueba de cargo." 24

\footnotetext{
${ }^{21}$ Esta norma corresponde a una reforma realizada por Ley Constitucional de 23 de noviembre de 1999 con el objetivo explícito de consolidar el modelo de debido proceso con garantías asentadas en la tradición anglosajona. Sobre el punto BOTERO, Martín, El sistema procesal penal acusatorio: funcionamiento y estructura prospectiva de Italia para América Latina, Bogotá: Ediciones Jurídicas Andrés Morales, 2008, pp. 78-87.

22 Constitución Política de Colombia de 1991 en http://www.senado.gov.co/images/stories/Informacion_General/constitucion_politica.pdf (última visita el 7 de enero de 2013).

${ }^{23}$ Solo para citar un ejemplo de la jurisprudencia en esta dirección véase sentencia de la Corte Suprema en causa rol $n^{\circ}$ 6631-2007 de 30 de enero de 2008. En materia doctrinaria puede verse, entre muchos otros, HORVITZ, María Inés; LÓPEZ, Julián, Derecho procesal penal Chileno tomo I, Santiago: Editorial Jurídica de Chile, 2002, pp. 70 y 71; y, TORO, Constanza, El debido proceso penal, Santiago: Ediciones Jurídicas de Santiago, 2009, pp. 45-55.

${ }^{24}$ Véase sentencia de la Corte Suprema en causa rol no $2866-2012$ de 17 de junio de 2013 considerando décimo cuarto. Otros ejemplos son: sentencia de la Corte Suprema en causa rol $\mathrm{n}^{\circ}$ 5116-2012 de 5 de septiembre de 2012 (especialmente ver considerando octavo); sentencia de la Corte Suprema en causa rol $\mathrm{n}^{\circ}$ 3795-2006 de 26 de septiembre de 2006. El considerando decimotercero de este fallo es sumamente explícito en este punto al señalar "Que, en el principio de contradicción se ha incluido, tradicionalmente, el derecho a probar y el de controlar la prueba del adversario. Ello no es incorrecto, pues, sobre todo el control de la prueba del adversario, representa una manifestación del contradictorio, a la vez que la facultad otorgada para demostrar los extremos que son esgrimidos para inhibir la imputación de que es objeto, o aminorar sus consecuencias, es una manifestación imprescindible de la posibilidad de oponerse a la ejecución penal.”
} 
DUCE, Mauricio. "El derecho a confrontación y uso de declaraciones emitidas en un juicio previo anulado".

De manera más específica, esta garantía fundamental también podría derivarse del inciso segundo del artículo $19 \mathrm{n}^{\mathrm{o}} 3$ de la Constitución que establece el derecho a la "defensa jurídica", la que ha sido también entendido de manera amplia por un sector de la doctrina ${ }^{25}$ y por jurisprudencia de la Corte Suprema. ${ }^{26}$ Como ya he señalado, el derecho de confrontación sería una de las manifestaciones específicas del derecho de defensa regulado en este inciso de nuestra Constitución.

A nivel legal, el derecho de confrontación se ha recogido en diversas disposiciones en el Código Procesal Penal que suelen ser analizadas por nuestra doctrina y la jurisprudencia bajo la noción de "principio de contradicción" o "principio contradictorio" y asociadas al derecho de defensa. ${ }^{27}$ Entre ellas pueden mencionarse los artículos 290, 325, 329, 330 y 338 del CPP.

Los alcances del principio de contradicción y su equivalencia con el derecho de confrontación son claros en nuestra doctrina. Así, por ejemplo, Chahuán señala respecto al mismo que

“...el principio contradictorio garantiza que la producción de las pruebas se hará bajo control de todos los sujetos procesales, con la finalidad que ellos tengan derecho de intervenir en dicha producción, formulando preguntas, observaciones, objeciones, aclaraciones y evaluaciones tanto respecto a la prueba propia como respecto de la de los otros". 28

Como se puede observar, se trata de una formulación con alcances casi idénticos a los que he planteado respecto al derecho a confrontación. Otro ejemplo de este tratamiento puede verse en Horvitz y López. Ellos señalan, a propósito del análisis de los principios del juicio oral, que

"La principal garantía de su obtención (la verdad) se confía al principio de contradicción, que consiste en la posibilidad real, por parte de la defensa, a la máxima refutación de la hipótesis acusatoria. En otras palabras, se trata del libre juego del

\footnotetext{
${ }^{25}$ Por ejemplo véase CHAHUÁN, Sabas, Manual de nuevo procedimiento penal, Santiago: LexisNexis, 2006, p. 26; TORO, Ibed, El derecho al debido proceso, Santiago: El Jurista Ediciones Jurídicas, 2012, p. 108.

${ }_{26}$ El considerando vigésimo de la sentencia de la Corte Suprema en causa rol n ${ }^{\circ} 2866-2012$ de 17 de junio de 2013 señala sobre este punto que "...el nuevo sistema procesal penal consagra como sustento básico el principio contradictorio que, como tal, está integrado al derecho de defensa del acusado".

${ }^{27}$ Por ejemplo BAYTELMAN, Andrés, "El juicio oral", en: VV.AA, Nuevo Proceso Penal, Santiago: Editorial Jurídica Conosur, 2000, pp. 227-282, pp. 249-250; MORENO, Leonardo, "Algunas consideraciones sobre el funcionamiento de la reforma procesal penal", en: DECAP, Mauricio; DUCE, Mauricio; MORENO, Leonardo; SÁEZ, Jorge, El modelo adversarial en Chile, Santiago: Thomson Reuters, 2013, pp. 67-218, pp. 108-111. En materia de jurisprudencia el considerando vigésimo de la sentencia de la Corte Suprema en causa rol no 2866-2012 de 17 de junio de 2013 señala, refiriéndose al principio contradictorio, que "De este modo, ha de considerarse que el referido principio se manifiesta claramente en el derecho de las partes al contraexamen de los testigos y peritos, lo cual no sólo está reconocido en las disposiciones antes citadas del Código procesal Penal, sino también en los tratados internacionales vigentes, como ocurre en el artículo $14 \mathrm{n}^{\circ}$ 3, letra e) del Pacto Internacional de derechos Civiles y Políticos y en el artículo 8 no2 letra f) de la Convención Americana Sobre Derechos Humanos".

${ }^{28}$ CHAHUÁN, Manual, cit. nota n ${ }^{\circ} 25$, p. 286.
} 
Polít. crim. Vol. 9, № 17 (Julio 2014), Art. 4, pp. 118-146.

[http://www.politicacriminal.cl/Vol_09/n_17/Vol9N17A4.pdf]

conflicto entre las partes en el proceso, portadoras de puntos de vista contrastantes o de intereses opuestos." 29

De esta forma enfatizan el aspecto institucional de este derecho, pero luego complementan su análisis destacando que se reconoce como una garantía central prevista en los tratados internacionales que ya he analizado. Por su parte, Moreno describe al principio contradictorio como:

“...aquel que consagra la facultad de ambas partes en disputa, en un plano de igualdad de condiciones proporcionada por la ley, de examinar, contra-examinar los hechos y dichos presentados por la parte contraria...,30

Junto con reiterar alcances similares a los anteriores en esta opinión se puede ver los vínculos que se trazan entre esta idea y la igualdad.

Concluyendo, me parece pacífico afirmar que el derecho de confrontación constituye una garantía básica que disponen los acusados en juicio que forma parte del núcleo duro de los mínimos que impone el debido proceso y que se trata de una garantía que ha sido reconocida ampliamente en el sistema internacional de protección de derechos humanos, el derecho comparado y nuestra legislación constitucional y procesal penal a pesar que ha sido tratada regularmente con una etiqueta distinta como lo es la del principio de contradicción o contradictoriedad. ${ }^{31}$ En consecuencia, una interpretación que no permita el ejercicio de esta garantía impide que el acusado cuente con un juicio justo y, por lo mismo, con un debido proceso.

\subsection{El contraexamen como un elemento básico del derecho de confrontación y sus alcances y objetivos:}

Establecido el punto anterior, corresponde determinar cuáles son los alcances del derecho a confrontación. Debido a que, como ya señalé, el origen de este derecho se encuentra en la tradición anglosajona o del Common Law, resulta de interés examinar brevemente los

\footnotetext{
${ }^{29}$ HORVITZ, María Inés; LÓPEZ, Julián, Derecho procesal penal chileno tomo Il, Santiago: Editorial Jurídica de Chile, 2004, p. 253. Concluyendo luego del texto citado que se trata de una garantía ampliamente recogida en las fuentes internacionales que ya he citado.

${ }^{30}$ MORENO, “Algunas consideraciones", cit. nota no 27, pp.108-109.

31 Creo a esta altura es necesario detenerme brevemente en una cuestión terminológica. A pesar de la equivalencia con que nuestra doctrina y jurisprudencia tratan al "derecho de confrontación" como "principio contradictorio" me parece que técnica y políticamente resulta conveniente adoptar con más fuerza la nomenclatura de "derecho de confrontación" y abandonar la noción de "principio contradictorio" para referirnos a este derecho como he hecho en este trabajo. Una primera razón es que la nomenclatura preferida pone un énfasis en la idea que estamos en presencia de un derecho fundamental y no solamente ante una directriz (como podría leerse detrás de la idea de "principio"). Además, la noción de derecho de confrontación tiene un largo desarrollo doctrinal y jurisprudencial en la tradición anglosajona de la cual proviene que me parece nos ofrece un marco mucho más adecuado para comprender las dimensiones del mismo en el contexto del tipo de sistema procesal penal acusatorio que hemos instalado en nuestro país. Finalmente, utilizar esta nomenclatura renueva las categorías procesales que se utilizan habitualmente en la materia y que han llevado a hacer sinónimo de este derecho fundamental nociones muy limitadas tales como la "bilateralidad de la audiencia" comúnmente utilizada por nuestra doctrina procesal más tradicional.
} 
DUCE, Mauricio. "El derecho a confrontación y uso de declaraciones emitidas en un juicio previo anulado".

alcances que se le han atribuido en los Estados Unidos, país que cuenta con una regla constitucional explícita en la materia (bastante similar además a las reguladas en la legislación internacional y comparada y que ha sido clara inspiradora de las mismas según he tenido oportunidad de mencionar). La jurisprudencia de la Corte Suprema y la doctrina de este país han entendido que la sexta enmienda implica tres cuestiones fundamentales: el derecho a contraexaminar a los testigos adversos; el derecho a que los testigos adversos declaren en presencia del acusado (cara a cara o face to face); y, el derecho a que cierta prueba de referencia de los fiscales no sea admitida a juicio. ${ }^{32}$

Como se puede apreciar, los alcances de este derecho son amplios, van más allá de lo que en una primera aproximación se pudiera pensar, incluyendo cuestiones novedosas para nuestra tradición tales como el derecho al cara a cara (o face to face), es decir, el derecho del acusado de estar en presencia física de quienes declaran en su contra y la exclusión de la prueba de referencia (al menos de una parte importante de ella), entendiendo que no es posible controvertir en el juicio una prueba que no está presente. ${ }^{33}$ Con todo, me interesa detenerme en el primero de estos alcances: el derecho a interrogar a los testigos adversos (de cargo) o, como ellos lo regulan explícitamente, el derecho a contraexaminar. Me parece que no necesito invertir mucho tiempo para justificar que se trata de la dimensión más obvia del derecho a confrontación, la que -por lo mismo- no es discutida en la actualidad en ningún sistema jurídico respetuoso del debido proceso. En efecto, la posibilidad de interrogar a quienes aportan información que perjudica al acusado parece constituir el núcleo central de la redacción de los tratados internacionales que ya he revisado y de la jurisprudencia y doctrina que se ha desarrollado en torno a ellos. Por lo mismo, no pareciera haber duda acerca que integra la columna vertebral básica del derecho a confrontación. Ello, por lo demás, se recoge en nuestro ordenamiento procesal penal de corte acusatorio en una modalidad muy similar a la de los Estados Unidos como lo es la posibilidad que tiene el acusado de realizar un contraexamen o cross-examination ${ }^{34}$ respecto de los testigos y peritos adversos. ${ }^{35}$

\footnotetext{
${ }^{32}$ En detalle sobre estos alcances véase DRESSLER, Joshua; MICHAELS, Alan, Understanding criminal procedure, New York: LexisNexis, 2006, pp. 237-256. Para un texto en castellano véase CHIESA, Ernesto, Derecho procesal penal de Puerto Rico y Estados Unidos vol. I, Puerto Rico: Editorial Forum, 1995, pp. 389433.

${ }^{33}$ El análisis específico de estas dimensiones más novedosas me alejaría del objetivo de este trabajo, pero baste señalar un ejemplo en materia de exclusión de la prueba de referencia. La legislación y práctica en los Estados Unidos es refractaria a admitir como prueba a juicio a testigos de oídas cuando se les pretende introducir con el propósito de acreditar la veracidad sobre las afirmaciones que escucharon. La no admisión de este tipo de prueba es materia de una regla clásica del derecho del mundo anglosajón conocida como la Hearsay Rule. Una explicación detallada de esta regla puede verse en PARK, Roger; LEONARD, David; GOLDBERG, Steven, Evidence law, St. Paul (Estados Unidos): Thomson West, 2004, pp. 255-415. En castellano y en referencia a las reglas de evidencia de Puerto Rico puede verse JIMÉNEZ, Rolando, Prontuario de derecho probatorio puertorriqueño, Puerto Rico: Ediciones Situm, 2010, pp. 453-544.

${ }^{34}$ Información sobre los alcances del cross-examination en los Estados Unidos puede verse en VIAL, "El derecho a confrontación", cit. nota n ${ }^{\circ} 4$, pp. 40-452.

${ }^{35}$ El artículo 329 de nuestro CPP regula con claridad esta materia en sus tres primeros incisos. En extenso sobre el reconocimiento legal en nuestro país del contraexamen véase VIAL, Pelayo, Técnicas y fundamentos del contraexamen en el proceso penal chileno, Santiago: Librotecnia, 2006, pp. 14 a 17. Sobre el vínculo entre el contraexamen y el derecho internacional de los derechos humanos véase FUENTES, Claudio, "Límites a la vigencia del principio contradictorio en los juicios de familia", Revista de Derecho Universidad Católica de la Santísima Concepción, no 21 (2010), pp. 49-63, pp. 50-54.
} 
Polít. crim. Vol. 9, № 17 (Julio 2014), Art. 4, pp. 118-146.

[http://www.politicacriminal.cl/Vol_09/n_17/Vol9N17A4.pdf]

En este contexto, la cuestión relevante a esclarecer es determinar los alcances de esta dimensión de la confrontación. También me parece que se trata de una cuestión bastante pacífica que no requiere una justificación extensa. En el ámbito internacional y comparado se ha entendido que esta dimensión del derecho de confrontación importa entregarle al acusado una oportunidad plena y efectiva para poder interrogar a los testigos adversos. ${ }^{36}$ Esto es, la posibilidad que el acusado pueda indagar críticamente la declaración del testigo o perito que aporta información que lo perjudica, ya sea cuestionando sus contenidos, agregando temas que ha omitido, precisando sus alcances, aportando elementos que permitan al tribunal pesar la credibilidad de quien emite las declaraciones, mostrando contradicciones, etc. Como se podrá apreciar, el contraexamen constituye un instrumento crucial para la confrontación de la prueba o, como han mencionado algunos, representa "la última confrontación.",37

La teoría que subyace detrás del contraexamen es que el ejercicio de este derecho permitirá obtener información de mayor calidad ya que a través de él se podrá escudriñar lo declarado por el testigo o perito en el examen directo y revelar potenciales falsedades, exageraciones, parcialidades, divergencias, contradicciones e inexactitudes de todo tipo en sus declaraciones iniciales. $^{38}$

En el contexto descrito, los objetivos posibles del contraexamen pueden ser divididos en dos grandes grupos. Por una parte, se encuentran los objetivos confrontacionales y, por la otra, los destinados a apoyar la teoría del caso de quien realiza esta actividad. ${ }^{39}$ El contraexamen clásico se suele asociar a los objetivos más bien confrontacionales y en ellos se expresa en buena medida la teoría que subyace y justifica a este derecho, por lo que me detengo en su identificación. A grandes rasgos, estos objetivos confrontacionales pueden apuntar a dos cuestiones: ${ }^{40}$

Desacreditar al testigo o perito: en este primer objetivo lo que se intenta hacer es cuestionar la credibilidad personal del testigo o perito, su valor como fuente de información. El mensaje que subyace a esta línea de contraexamen es, en lo fundamental, "este testigo o perito no vale nada" y, por lo mismo, su testimonio no debiera ser considerado por el tribunal. Por ejemplo,

\footnotetext{
${ }^{36}$ Entre otros véase DECASTRO, Alejandro, El contrainterrogatorio, Colombia: Librería Jurídica Comlibros, 2005, pp. 200; CHIESA, Derecho procesal penal, cit. nota $\mathrm{n}^{\circ} 32$, p. 398; VAN DIJK/VAN HOOF/VAN RIJN/ZWAAK, Teoría y práctica, cit. nota $\mathrm{n}^{\circ} 17$, p. 432 (quienes se refieren a la jurisprudencia de la Corte Europea en la materia señalando que en ella esta garantía se trata de contar con "...una oportunidad adecuada y apropiada de oponerse y cuestionar a los testigos en su contra...").

${ }_{37}^{37}$ DECASTRO, El contrainterrogatorio, cit. nota $\mathrm{n}^{\circ} 36, \mathrm{p} .2$ (quien sobre este punto cita a Romero).

${ }^{38}$ En este sentido véase VIAL, "El derecho a confrontación", cit. nota ${ }^{\circ}{ }^{4}, \mathrm{p}$. 455 , quien cita extensamente jurisprudencia de los Estados Unidos sobre el punto.

${ }_{39}$ Con más detalle sobre este tema véase BAYTELMAN, Andrés; DUCE, Mauricio, Litigación Penal Juicio Oral y Prueba, Santiago: Ediciones Universidad Diego Portales, 2005, pp. 160-164; BLANCO, Rafael; DECAP; Mauricio, MORENO; Leonardo; ROJAS, Hugo, Litigación estratégica en el nuevo proceso penal, Santiago: LexisNexis, 2005, pp. 206- 208; LORENZO, Leticia, Manual de litigación, Buenos Aires: Ediciones Didot, 2012, pp. 209-2011; VIAL, Técnicas y fundamentos, cit. nota no 35, pp. 35-44.

${ }^{40}$ Vale la pena señalar que estos objetivos están explícitamente regulados en nuestro CPP en el artículo 309 inciso primero al establecer que es posible para los intervinientes dirigir preguntas a los testigos tendientes a demostrar su falta de credibilidad, su falta de imparcialidad u otro defecto de idoneidad.
} 
DUCE, Mauricio. "El derecho a confrontación y uso de declaraciones emitidas en un juicio previo anulado".

cuando se afirma que el testigo o perito tiene un interés directo en el asunto que hace que su declaración sea motivada o no imparcial.

Desacreditar al testimonio o pericia: en este objetivo se trata de atacar la credibilidad no ya de la persona del testigo o perito, sino del testimonio que ha prestado en juicio. Allí donde el mensaje que subyacía para el tribunal cuando se trataba de desacreditar al testigo era "este testigo o perito no vale nada", ahora el mensaje es más bien "este testigo o perito es seguramente una buena persona o un profesional calificado (tratándose de la pericia), pero en este caso concreto está en un error" y, por lo mismo, su testimonio tampoco debiera ser considerado por el tribunal. Por ejemplo, cuando se afirma que las condiciones de visibilidad no permitían apreciar con claridad lo que ha señalado el testigo o cuando el perito no utilizó el método prescrito por la disciplina para practicar tal o cuál examen.

Se podrá observar que la posibilidad de lograr estos objetivos supone que el acusado disponga de un conjunto de herramientas que permitan darle la oportunidad plena y efectiva de interrogar a los testigos y peritos adversos. Para cumplir con la función que el sistema acusatorio le asigna al contraexamen, consiguientemente para satisfacer el derecho a confrontación, no basta con la simple posibilidad que se permita al acusado hacer preguntas, sino que se debe regular un conjunto de supuestos para que esa posibilidad de interrogar ofrezca una oportunidad seria de cuestionamiento a la declaración del testigo o perito. Un riesgo de interpretación formalista de esta garantía es el entender que el derecho se satisface con la sola oportunidad de hacer preguntas de contraexamen. La garantía exige bastante más que aquello, ya que se necesita no sólo una oportunidad sino que esta sea plena y efectiva. $^{41}$

Estas condiciones obligan a los sistemas jurídicos a desarrollar un conjunto de herramientas que garanticen el ejercicio efectivo del derecho al contrainterrogatorio. Dentro de ellas nuestro ordenamiento jurídico se ha hecho cargo de contemplar las siguientes: el descubrimiento oportuno de la evidencia (acceso a información) que permita al acusado preparar adecuadamente el contraexamen (por ejemplo en los artículos 182 y 260 del CPP); la posibilidad de formular preguntas sugestivas durante su desarrollo de manera de tener mayor control del mismo (artículo 330 del CPP); la posibilidad de introducir "prueba sobre prueba" (artículo 336 inciso segundo del CPP); y, finalmente, el uso de declaraciones previas formuladas por el testigo con el propósito de manifestar contradicciones o inconsistencias con la declaración actual (artículo 332 del CPP). Sin herramientas de este tipo se pone en cuestión seriamente la posibilidad de permitir que el contraexamen cumpla su función y, por lo mismo, se satisfaga el derecho a confrontación.

\footnotetext{
${ }^{41}$ La Corte Suprema de nuestro país se ha pronunciado hace tiempo en la misma dirección. Así, por ejemplo, ha señalado "Que, en otro orden de ideas, el sentenciador incurre en un error al suponer que el derecho de defensa del imputado se salvaguarda simplemente con la facultad que tiene para contrainterrogar a los testigos del querellante en la audiencia de estilo. Su derecho de defensa pasa también por tener la oportunidad y el tiempo suficiente para su debida preparación." La Corte luego asocia esta preparación a la posibilidad real de contrainterrogar en materias de credibilidad e idoneidad del testigo. Véase sentencia de la Corte Suprema en causa rol $n^{\circ} 2345-2005$ de 13 de julio de 2005 (considerando quinto).
} 
Polít. crim. Vol. 9, № 17 (Julio 2014), Art. 4, pp. 118-146.

[http://www.politicacriminal.cl/Vol_09/n_17/Vol9N17A4.pdf]

No puedo detenerme en el análisis detallado de todas estas cuestiones ya que se perdería el foco de este trabajo, pero me interesa destacar que en esta misma dirección se ha pronunciado nuestra Corte Suprema. Se trata de un caso en el que se dio lugar a un recurso de nulidad fundado en la causal del artículo 373 a) del CPP. En el juicio la defensa pudo contraexaminar a una testigo, sin embargo no había tenido acceso previo a información mínima que le permitiera preparar el contraexamen debido a la inexistencia de registros que dieran cuenta de declaraciones previas de la misma e incluso su existencia con un nivel mínimo de individualización. ${ }^{42}$ La Corte anuló el caso por considerar que esta falta de acceso impidió el adecuado ejercicio del derecho. La Corte señaló:

"El artículo 93 del Código Procesal Penal, en su literal e), reconoce el derecho del imputado a imponerse del contenido de la investigación, lo que resulta necesario no sólo para la elaboración de la estrategia defensiva o la teoría del caso, sino que para la presentación adecuada a la audiencia de preparación del juicio, como asimismo, para el desarrollo de los contrainterrogatorios de los testigos de cargo, puesto que no es posible pretender que la defensa esté en condiciones de elaborar una estrategia defensiva o adoptar alguna decisión sobre aquella, si no conoce todos los elementos de cargo. El escenario que le muestra la investigación del fiscal y que es la que recibe junto con la acusación -con el tiempo suficiente garantizado por el legislador antes de la audiencia de preparación de juicio-, es el que le permite discernir la mejor forma de enfrentar el juicio y defender los derechos del acusado." 43

Más adelante, la Corte concluyó sobre el punto:

"Que en conclusión, la correcta comprensión del ejercicio del derecho a defensa del imputado y del debido proceso que conlleva como garantías mínimas el derecho a conocer en detalle la imputación y los elementos de cargo, así como el derecho a contrainterrogar a los testigos de cargo, supone el acceso sin restricciones al contenido íntegro de la investigación (salvo los casos excepcionales de secreto) y ello supone necesariamente el acceso a la información completa.

Al respecto, resulta reveladora la expresión del sistema norteamericano que describieron nuestros legisladores al referirse a la audiencia de preparación de juicio como el discovery o "mostrarse las cartas", cuando explicaban que era imposible que el fiscal ocultara algún medio de prueba. (Informe de la Comisión de Constitución, Pág. 368, Historia de la Ley)."44

Siguiendo la lógica de la Corte, el sólo hecho que la defensa haya tenido posibilidad de contrainterrogar a la testigo no fue suficiente para dar por satisfecho el cumplimiento del derecho a confrontar (derecho a defensa y debido proceso en la sentencia). Como señalé, la defensa había tenido la oportunidad de contraexaminar a la testigo en cuestión. El punto es que, para que ese ejercicio pudiera satisfacer al debido proceso, suponía también exigencias adicionales tales como el oportuno descubrimiento o acceso a la información necesaria para preparar el contrainterrogatorio.

\footnotetext{
${ }^{42}$ Sentencia de la Corte Suprema en causa rol no 5116-2012 de 5 de septiembre de 2012.

${ }^{43}$ Sentencia de la Corte Suprema en causa rol n ${ }^{\circ}$ 5116-2012 de 5 de septiembre de 2012, considerando octavo.

${ }^{44}$ Sentencia de la Corte Suprema en causa rol n ${ }^{\circ}$ 5116-2012 de 5 de septiembre de 2012, considerando decimoprimero.
} 
DUCE, Mauricio. "El derecho a confrontación y uso de declaraciones emitidas en un juicio previo anulado".

La doctrina nacional, por su parte, ha destacado también la trascendencia de las otras herramientas mencionadas para permitir que el contraexamen satisfaga el derecho a confrontación. Por ejemplo, varios autores han enfatizado la centralidad que tiene la posibilidad de formular preguntas sugestivas para esto. ${ }^{45}$

En lo que sigue me focalizaré en el análisis de una herramienta particular de las mencionadas que constituye el núcleo central de este trabajo: el uso de las declaraciones previas.

\section{El uso de declaraciones previas como supuesto para el ejercicio del derecho al contraexamen y su regulación en nuestro CPP.}

En esta sección me hago cargo en forma más específica del rol que cumple el uso de las declaraciones previas de los testigos y peritos en el ejercicio del derecho a confrontación. Como señalaba previamente, esta herramienta constituye uno de los pilares centrales que permiten transformar al interrogatorio de un testigo o perito en una oportunidad plena y efectiva de contraexamen.

\subsection{Las declaraciones previas su rol en el ejercicio del derecho a contraexaminar:}

El uso de las declaraciones previas como herramienta de contraexamen tiene dos supuestos básicos: que exista una declaración previa prestada por el testigo o perito que comparece a juicio y que exista una discrepancia o contradicción entre ambas versiones. Acerca de lo primero, la dinámica de funcionamiento de los sistemas procesales penales contemporáneos favorece que respecto a los testigos y peritos, especialmente cuando se trata de aquellos que presenta el Ministerio Público, se cuente con declaraciones previas registradas por el sistema (por ejemplo debido a que han declarado ante el propio Ministerio Público durante el desarrollo de la investigación). Por lo mismo, estamos en presencia de un escenario habitual de trabajo y una situación que se produce con frecuencia.

Para comprender la relevancia y objetivos que cumple esta herramienta del contrainterrogatorio vale la pena recordar algunas cuestiones generales analizadas. Ya he dicho que uno de los objetivos más clásicos del contraexamen consiste en impugnar o atacar la credibilidad del testigo o perito que presta declaración en juicio. Además, señalé que dicho objetivo está explícitamente reconocido en nuestro CPP en su artículo 309 inciso primero. Las estrategias posibles para lograr este objetivo de desacreditación son de la más variada índole, por ejemplo, cuando el contrainterrogatorio permite demostrar que se trata de un testigo o perito que es parcial, que se trata de una persona que tiene reputación de

\footnotetext{
${ }^{45}$ Me parece que hoy existe bastante unanimidad sobre esto en nuestra doctrina. Por ejemplo, véase BAYTELMAN, "El juicio", cit. nota $\mathrm{n}^{\circ}$ 27, p. 268; BLANCO/DECAP/MORENO/ROJAS, Litigación estratégica, cit. nota $\mathrm{n}^{\circ}$ 39, pp. 213-214; DUCE, Mauricio; MARIN, Felipe; RIEGO, Cristián, "Reformas a los procesos civiles orales: consideraciones desde el debido proceso y la calidad de la información", en: VV.AA, Justicia Civil: Perspectivas para una Reforma en América Latina, Santiago: Centro de Estudios de Justicia de las Américas, 2008, pp. 13-94, pp. 52; MATURANA, Cristián; MONTERO, Raúl. Derecho procesal penal tomo II, Santiago: AbeledoPerrot, 2010, p. 1011; ORTEGA, Waldo, Litigación oral para el proceso penal, Santiago: Ril Editores, 2012, pp. 139-140; VIAL, "El derecho a confrontación”, cit. nota no 4, pp. 456-457.
} 
Polít. crim. Vol. 9, № 17 (Julio 2014), Art. 4, pp. 118-146.

[http://www.politicacriminal.cl/Vol_09/n_17/Vol9N17A4.pdf]

poco sincero o derechamente de mentiroso, que tiene alguna motivación o interés que afecta su declaración, entre otras posibles. En este contexto, una de las modalidades más efectivas y poderosas de impugnación de la credibilidad de testigos y peritos pasa precisamente por el uso de las declaraciones previas. Si alguien ha declarado previamente sobre un punto en condiciones que aseguran la confiabilidad de dicha declaración, por ejemplo, debido a que fueron prestadas ante un tribunal rodeado de todas las garantías, y luego cuando en el juicio el contenido de ese punto cambia o se altera de manera significativa, es natural que surjan dudas importantes la calidad de la información que el tribunal recibe y que se generen cuestionamientos obvios a la credibilidad del testigo. ${ }^{46} \mathrm{La}$ forma de mostrarle esas dudas o cuestionamiento al tribunal será por medio de hacerle conocer la existencia y contenido de las declaraciones previas. En este tipo de hipótesis el uso de declaraciones previas será la principal arma de desacreditación que dispone el acusado.

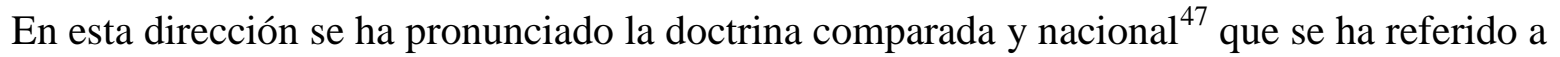
la materia. Por ejemplo, Chiesa ha señalado:

"El medio tal vez más eficaz para impugnar la credibilidad de un testigo es traer ante la consideración del juzgador las declaraciones anteriores del testigo incompatibles con su testimonio en Corte. Esto no sólo pone en entredicho la credibilidad del testigo en relación con el asunto específico al que se refiere la contradicción, sino también la credibilidad general del testigo." $" 48$

Otro autor, con el objetivo de enfatizar la importancia de esta herramienta, ha señalado se trata de "la más potente munición en el arsenal del contrainterrogador." 49 Por lo mismo, se entiende que forma parte central del derecho a contraexaminar. Si es que en un caso existe una declaración previa, la lógica que subyace a los sistemas acusatorios y los valores que justifican al derecho de confrontación suponen la posibilidad de utilizar esa declaración para controlar el contenido de las declaraciones actuales.

La importancia del uso de declaraciones previas para permitir una oportunidad de contraexamen plena y efectiva ha llevado a un amplio reconocimiento de la materia en el derecho comparado, incluso en países con tradiciones procesales diversas como los Estados Unidos, Alemania e Italia. Veamos rápidamente como regulan el punto estas legislaciones.

\footnotetext{
${ }^{46}$ Park, Leonard y Goldberg señalan "Mostrar que el testigo ha dicho diferentes cosas en diferentes momentos arroja dudas sobre su credibilidad, independiente si las declaraciones previas son creíbles o no. Inconsistencias sobre un hecho arrojan una sombra de dudas sobre la confiabilidad del testigo sobre los otros hechos." PARK/LEONARD/GOLDBERG, Evidence law, cit. nota nº 33, p. 472 (la traducción es del autor).

${ }^{47}$ Véase, entre otros, BAYTELMAN/DUCE, Litigación penal, cit. nota $\mathrm{n}^{\circ} 39$, p. 326; HERMOSILLA; Francisco, “¿Cuáles son las Excepciones a la práctica de la prueba en juicio oral?”, en: MIRANDA, Manuel; CERDA, Rodrigo; HERMOSILlA, Francisco, Práctica de la prueba en el juicio oral, Santiago: Librotecnia, 2012, pp. 183-196, p.194; ORTEGA, Litigación oral, cit. nota $\mathrm{n}^{\circ} 45$, p. 165; y, VIAL, Técnicas y fundamentos, cit. nota $\mathrm{n}^{\circ} 35$, pp. 214-222.

${ }^{48}$ CHIESA, Ernesto, Derecho procesal penal de Puerto Rico y Estados Unidos vol. III, Puerto Rico: Editorial Forum, 1995, p. 326.

${ }^{49}$ Schwartz citado por DECASTRO, El contrainterrogatorio, cit. nota $\mathrm{n}^{\mathrm{o}} 36, \mathrm{p}$. 561, quien en todo caso comparte estas afirmaciones.
} 
DUCE, Mauricio. "El derecho a confrontación y uso de declaraciones emitidas en un juicio previo anulado".

En los Estados Unidos la posibilidad de utilizar declaraciones previas para manifestar contradicciones con las declaraciones en juicio tienen una regulación bastante permisiva. En efecto, se trata de un tema contemplado en la sección 613 de las Reglas Federales de Evidencia $^{50}$, según la cual se permite confrontar al testigo o perito si es que existe una contradicción (ya sea positiva o por omisión) ${ }^{51}$ entre lo que ha declarado en forma previa al juicio (ya sea por escrito u oralmente y ante cualquier autoridad o persona). La única exigencia sustantiva de esta regla es que la declaración previa tenga una tendencia a desacreditar el testimonio del testigo o perito ${ }^{52}$ o arroje una luz sobre la credibilidad del testigo. ${ }^{53}$ La operatividad de esta herramienta ha sido ampliada por diversos casos conocidos por la Corte Suprema de los Estados Unidos que han establecido que incluso declaraciones previas obtenidas con violación de diversas garantías fundamentales, que por lo general debiera llevar a la exclusión de esa información, puedan ser utilizadas sólo para los efectos de atacar credibilidad de un testimonio. ${ }^{54}$

En Alemania, el parágrafo 253 de la Ordenanza Procesal Penal regula la materia admitiendo la lectura de actas en donde consten declaraciones previas de testigos o peritos para efectos de mostrar contradicciones con las declaraciones en el juicio. ${ }^{55}$ Se trata también de una cláusula abierta que parece favorecer el uso de declaraciones previas en la medida que haya contradicciones.

En Italia, el artículo 500.1 del Código de Procedimiento Penal permite la lectura de declaraciones previas para efectos de confrontar a un testigo en juicio en la medida que ya haya prestado declaración sobre el punto en la audiencia y esa declaración conste en los registros o carpeta de investigación que lleva el Ministerio Público. La declaración previa pueden haber sido prestadas en la etapa de investigación, la audiencia preliminar e incluso los incidentes probatorios (casos de prueba anticipada en nomenclatura nacional). ${ }^{56}$

\footnotetext{
${ }^{50}$ En detalle sobre esta regla puede verse GIANELLI, Paul, Understanding Evidence, Estados Unidos: LexisNexis, 2006, pp. 281-288; y, PARK/LEONARD/GOLDBERG, Evidence law, cit. nota $\mathrm{n}^{\circ}$ 33, pp. 472478. En castellano, pero referido a la regla 611 de las Reglas de Evidencia Puerto Rico de 2010, en todo caso similares a la regla 613 en análisis, puede verse JIMENEZ, Prontuario de derecho probatorio, cit. nota ${ }^{\circ} 33$, pp. 396-399.

${ }^{51}$ Se entiende que hay una contradicción positiva cuando un testigo afirma algo en la declaración previa ("el auto era rojo") y luego cambia dicha versión en juicio ("el auto era azul"). Se trata de una contradicción por omisión cuando en la declaración previa el perito o testigo nada dice sobre una determinada cuestión y luego en juicio las agrega (por ejemplo cuando al describir al acusado no había señalado en su declaración previa alguna característica física de relevancia que luego sí es mencionada en juicio).

${ }_{52}$ VIAL, "El derecho a confrontación", cit. nota n $\mathrm{n}^{\circ}$ 4, p. 461.

${ }^{53}$ PARK/LEONARD/GOLDBERG, Evidence law, cit. nota n ${ }^{\circ} 33$, p. 473.

${ }_{55}^{54}$ GIANELLI, Understanding, cit. nota ${ }^{\circ}$ 50, p. 286.

${ }^{55}$ La disposición señala "Lectura de actas para favorecer el recuerdo. (1) Si declarara un testigo o perito que ya no se acuerda de un hecho, podrá leerse la parte del acta relativa a ello sobre su anterior interrogatorio, con el fin de ayudar la memoria. (2) Lo mismo podrá ocurrir cuando no pudiere comprobarse de otra manera una contradicción sobrevenida en el interrogatorio con la anterior declaración, sin interrupción de la vista principal, o no pudiera ser solventada". Véase GÓMEZ COLOMER, Juan Luis, El proceso penal alemán: introducción y normas básicas, Barcelona: BOSCH, 1985, p. 363. Véase también ROXIN, Claus, Derecho procesal penal, Buenos Aires: Editores del Puerto, 2000, p. 397.

${ }^{56}$ Con mayores detalles sobre el punto véase BOTERO, El sistema procesal penal, cit. nota $\mathrm{n}^{\circ} 21$, pp. 543545; y PLOTINO, Francesco, El debate en el nuevo Código de Procedimiento Penal, Córdoba (Argentina): Editorial Mediterránea, 2001, pp. 135-142.
} 
Polít. crim. Vol. 9, № 17 (Julio 2014), Art. 4, pp. 118-146.

[http://www.politicacriminal.cl/Vol_09/n_17/Vol9N17A4.pdf]

Lo que reflejan estas legislaciones tomadas como ejemplo es que razones tanto desde el punto de vista de las garantías individuales (el derecho a confrontación), como desde la óptica de la eficiencia y calidad del sistema (la calidad de la información para resolver los casos), apuntan a favorecer un amplio uso de declaraciones previas en juicio en el caso que existan contradicciones que pudieren afectar la credibilidad de un testigo o perito. El formato o lugar en donde se haya prestado dicha declaración previa no resulta relevante en la medida en que tenga asegurada un nivel de confiabilidad respecto a su contenido. Lo que sí se considera central es la posibilidad del tribunal de conocer las discrepancias entre las versiones de manera que pueda pesar la credibilidad de los testigos con toda la información disponible sobre la mesa.

Esta misma lógica también se ha traspasado a los sistemas procesales penales reformados en América Latina en donde es común encontrar reglas que permiten un uso amplio de las declaraciones previas para efectos de manifestar inconsistencias o contradicciones con las declaraciones del testigo o perito en juicio. Ejemplos son el artículo 241 inciso segundo del Código Procesal Penal de Provincia de Buenos Aires de 1998, ${ }^{57}$ los artículos 393 b) y 403.4 del Código de Procedimiento Penal de Colombia de $2004,{ }^{58}$ el artículo 378.6 del Código Procesal Penal de Perú de $2004^{59}$ y el artículo 401 del Código Procesal Penal de Panamá de $2008 .^{60}$ Todos ellos dan cuenta que en el contexto de los sistemas acusatorios implementados en la región, la posibilidad de utilizar declaraciones previas para evidenciar contradicciones o inconsistencias en la declaración de un testigo son considerados elementos claves para el ejercicio de un derecho a un pleno y efectivo contraexamen.

\subsection{Las declaraciones previas en nuestro sistema procesal penal:}

Las ideas han sido claramente adoptadas por nuestra legislación procesal penal en diversas disposiciones del CPP. Las dos principales son las contenidas en el artículo 330 inciso segundo y el artículo 332 del CPP.

\footnotetext{
${ }^{57}$ La norma señala textualmente "Toda otra prueba que se pretenda introducir al juicio por su lectura no tendrá ningún valor, sin perjuicio de la presentación de documentos al testigo, perito o imputado para facilitar su memoria o dar explicaciones de lo que allí consta, previa autorización del tribunal. En todo caso se valorarán los dichos vertidos al respecto en la audiencia".

${ }^{58}$ El artículo 393 establece las reglas sobre el contrainterrogatorio señalando en su letra b) que "Para contrainterrogar se puede utilizar cualquier declaración que hubiese hecho el testigo sobre los hechos en entrevista, en declaración jurada durante la investigación o en la propia audiencia de juicio oral". Esta norma es complementada por el artículo 403 que regula la impugnación de credibilidad del testigo sosteniendo que ella se puede cuestionar la credibilidad del testigo ante un juez en relación a "4.Manifestaciones anteriores del testigo, incluidas aquellas hechas a terceros, entrevistas, exposiciones, declaraciones juradas o interrogatorios en audiencias ante el juez de control de garantías".

${ }^{59}$ La norma señala textualmente: "Artículo 378. Examen de testigos y peritos. 6. Si un testigo o perito declara que ya no se acuerda de un hecho, se puede leer la parte correspondiente del acto sobre su interrogatorio anterior para hacer memoria. Se dispondrá lo mismo si en el interrogatorio surge una contradicción con la declaración anterior que no se puede constatar o superar de otra manera"

${ }^{60}$ La norma señala textualmente : "Cuando fuere necesario para la ayuda de memoria de un testigo o perito, cuando esté prestando declaración o para demostrar o superar contradicciones o para solicitar aclaraciones pertinentes, se podrá leer en el interrogatorio o contrainterrogatorio parte o partes de sus declaraciones anteriores prestadas ante los organismos de policía, el Fiscal o el Juez de garantías"
} 
DUCE, Mauricio. "El derecho a confrontación y uso de declaraciones emitidas en un juicio previo anulado".

El inciso segundo del artículo 330 del CPP establece que "Durante el contrainterrogatorio, las partes podrán confrontar al perito o testigo con sus propios dichos u otras versiones de los hechos presentadas en el juicio" (el subrayado es mío). Se trata de una norma que manifiesta una clara orientación de nuestro legislador por permitir un ejercicio de confrontación intenso de las declaraciones de peritos o testigos en el juicio oral. En efecto, según se puede apreciar del tenor literal de la disposición citada, nuestro CPP establece un derecho amplio de confrontación al permitir que, para efectos de llevar adelante el contrainterrogatorio, se puedan utilizar los propios dichos del perito o testigo sin poner restricciones o limitaciones específicas. ${ }^{61}$

Hay tres elementos de la disposición en análisis que es necesario precisar ya que dan cuenta de la amplitud de la misma y su pertinencia para el tema de este trabajo. El primero se refiere al momento en que esta norma entra en juego, que corresponde al contrainterrogatorio que se realiza en el juicio oral. El segundo elemento se refiere al alcance de la expresión "dichos". Un "dicho" está conformado por una versión entregada por el propio testigo o perito en forma previa. Esto, en mi opinión, hace que la expresión "dicho" se asimile a la noción de declaraciones previas. El tercer elemento se refiere al propósito con el que pueden ser utilizados los "dichos". El CPP habla que el uso de los "dichos" está autorizado para "confrontar" al testigo o perito, es decir, manifestar discrepancias o contradicciones de cualquier tipo entre la declaración actual con la que ha hecho en forma previa. En ninguna parte de la disposición el CPP hace distinción alguna respecto al momento, lugar o formato en que han sido expedidos esos "dichos". Esto sería consistente con las reglas que he revisado se contemplan en el ámbito comparado en materia de uso de declaraciones previas, especialmente el caso de los Estados Unidos.

El artículo 332 del CPP complementa la disposición anterior al regular la posibilidad de utilizar declaraciones previas para objetivos más amplios que los de la pura confrontación. En efecto, al menos dos objetivos son posibles de ser identificados en esta regla. Un primero objetivo de esta norma es autorizar el uso específico de declaraciones previas con el propósito de apoyar la memoria de testigos y peritos. El segundo objetivo, pertinente para el tema de este trabajo, autoriza el uso de estas declaraciones previas para demostrar o superar contradicciones. Me detengo sólo en este segundo objetivo ya que regula la hipótesis que se analiza aquí.

El artículo 332 del CPP también se estructura sobre la base de exigencias que apuntan en la misma dirección de las contenidas en el artículo 330. En primer lugar, la posibilidad de utilizar las declaraciones previas surge en el contexto de la declaración que actualmente presta en juicio el testigo o perito ("sólo una vez que el testigo hubiere prestado declaración"). En segundo lugar, la norma autoriza la lectura de las declaraciones previas que hubieran sido otorgadas frente a ciertas autoridades específicas (prestadas ante el fiscal, el abogado asistente del fiscal o ante el juez de garantía). ${ }^{62}$ Finalmente, la norma exige un

\footnotetext{
${ }^{61}$ En este mismo sentido sentencia de la Corte Suprema en causa rol no 2866-2012 de 17 de junio de 2013 , considerando vigésimo.

${ }^{62}$ Volveré sobre este tema más adelante. Véase infra 3.2.
} 
Polít. crim. Vol. 9, № 17 (Julio 2014), Art. 4, pp. 118-146.

[http://www.politicacriminal.cl/Vol_09/n_17/Vol9N17A4.pdf]

propósito específico asociado directamente con los fundamentos del derecho a confrontación ("para demostrar o superar contradicciones"). ${ }^{63}$

Lectura armónica de ambas disposiciones a la luz del prisma que impone el debido proceso, las normas internacionales y constitucionales hace concluir que nuestro sistema jurídico considera el uso de las declaraciones previas con el propósito de mostrar contradicciones del testigo o perito como una herramienta básica del contraexamen, sin la cual esta actividad, como ha dicho al Corte Suprema a propósito del descubrimiento, no es practicable. ${ }^{64}$ Existiendo declaraciones previas de un testigo o perito y habiendo en su declaración actual una contradicción o inexactitud de cualquier tipo con la misma, nuestro sistema jurídico considera que es valioso poder utilizar dicha declaración previa para mostrarle al tribunal la diferencia entre ambas. Si ello no se permite no sólo se vulnera el debido proceso (específicamente el derecho de confrontación que forma parte del derecho de defensa) sino que también el sistema se priva de información esencial para poder tomar una decisión informada y de calidad en el caso.

Esta posición es la que de manera explícita ha sido adoptada por la Corte Suprema en su decisión de 17 de junio de 2013 que ya he comentado. Allí la Corte asume que el uso de declaraciones previas del juicio anulado es “...indispensable...para permitir el correcto ejercicio del contraexamen a que tenía derecho la defensa..."

Siguiendo la línea de argumentación que he desarrollado, debe concluirse que el debate sobre el uso que la parte acusada puede hacer de las declaraciones previas en un juicio oral es siempre, en primer lugar, un debate sobre el ejercicio de un derecho fundamental. Por lo tanto, la posibilidad de limitar el ejercicio del mismo debiera ser excepcional y estar particularmente fundada por el tribunal. Sobre el punto la propia Corte Suprema ha dicho:

“Tratándose de derechos o garantías procesales que integran el debido proceso, no es factible realizar respecto de ellos una interpretación restringida que entrabe las facultades de defensa y en ese sentido, cuando la ley autoriza el contraexamen con declaraciones previas, sin hacer distinción alguna, no corresponde a los jueces hacer distingos que reduzcan o limiten el legítimo ejercicio de los derechos reconocidos en la Constitución, la ley y los tratados internacionales vigentes."

En este contexto, la negativa absoluta de un tribunal de utilizar las declaraciones previas existiendo contradicciones es derechamente problemática, más si la decisión se toma sin ponderación de los valores que están en juego. El recurrir a interpretaciones formales sobre el alcance de los efectos de la nulidad del juicio previo no parece hacerse cargo del problema de fondo y, por lo tanto, no puede constituir una razón válida para suprimir del todo el ejercicio del derecho en análisis. Para limitar (no impedir por completo) al acusado de su derecho a tener una oportunidad plena y efectiva para desacreditar a los testigos o

\footnotetext{
${ }^{63}$ Un análisis general de estos elementos puede verse el ORTEGA, Litigación oral, cit. nota ${ }^{\circ}$ 45, pp. 166182.

${ }^{64}$ Sentencia de la Corte Suprema en causa rol $\mathrm{n}^{\mathrm{o}}$ 5116-2012 de 5 de septiembre de 2012 ya citada previamente.

${ }^{65}$ Sentencia de la Corte Suprema en causa rol no 2866-2012 de 17 de junio de 2013, considerando vigésimo.

${ }^{66}$ Sentencia de la Corte Suprema en causa rol no 2866-2012 de 17 de junio de 2013, considerando vigésimo.
} 
DUCE, Mauricio. "El derecho a confrontación y uso de declaraciones emitidas en un juicio previo anulado".

peritos en un punto crucial y sensible de su credibilidad sólo sería admisible considerar razones de fondo que apuntaran a valores de al menos igual relevancia que el derecho a confrontación.

\section{La impertinencia de algunas objeciones potenciales:}

A la luz de las consideraciones precedentes, parece indispensable revisar críticamente los principales argumentos u objeciones que podrían esgrimir para no dar lugar al uso de las declaraciones previas de un juicio. El análisis de estos mismos nos permitirá determinar si se trata de objeciones razonables o, por el contrario, que no constituyen buenas razones para limitar el ejercicio de un derecho fundamental.

\subsection{Los efectos de la nulidad.}

Como ya señalé, la principal causa que se suele invocar para impedir el uso de las declaraciones de un juicio anulado es que, debido a la anulación del primer juicio, se ha generado una inexistencia jurídica de todo lo ocurrido en el mismo que también lleva aparejada una inexistencia fáctica. Esta línea de razonamiento ha llevado a considerar que no se podrían utilizar declaraciones previas, ya que ellas no tienen ni existencia jurídica y tampoco fáctica.

Me parece que un problema severo de esta objeción es que ella no enfoca adecuadamente la cuestión en debate ya que no se hace cargo en ningún momento del problema de derechos fundamentales que genera. Es decir, para poder tener algún nivel mínimo de plausibilidad este argumento debiera hacerse cargo de las consecuencias que produce para el ejercicio del derecho a contraexaminar, cuestión que no hace.

Junto con este primer aspecto, hay que apuntar se trata de una interpretación jurídicamente errónea sobre los alcances de la nulidad. Tal como lo ha señalado la doctrina:

“...la nulidad es un concepto o categoría jurídico, representativo de la declaración de invalidez de un acto para producir ciertos efectos jurídicos, y, por ende, no predica ni significa la inexistencia del acto (categoría perteneciente a otro mundo), cómo si él no se hubiera realizado." 67

Esto significa en la práctica que existe una enorme distancia entre sostener que para unos ciertos efectos jurídicos un acto se ha declarado nulo que ese acto no haya existido y no se pueda aprovechar para otras cuestiones diversas a las que generaron la nulidad.

El trabajo que he citado de Pelayo Vial ejemplifica este alcance limitado de la nulidad recurriendo a dos situaciones en que nuestro ordenamiento jurídico, no obstante haber declarado la nulidad de un juicio oral, considera que lo ocurrido previamente sí tendrá influencia en el juicio lo que daría precisamente cuenta que los efectos de ésta no son

\footnotetext{
${ }^{67}$ VIAL, "El derecho a confrontación", cit. nota n ${ }^{\circ} 4$ p. 471, quien para arribar a esta conclusión cita a parte de la doctrina más especializada en el punto en América Latina (Maier, Clariá Olmedo, Cafferata Nores y De la Rúa).
} 
Polít. crim. Vol. 9, № 17 (Julio 2014), Art. 4, pp. 118-146.

[http://www.politicacriminal.cl/Vol_09/n_17/Vol9N17A4.pdf]

absolutos. En primer lugar, se refiere a situaciones en que junto con declarar la nulidad la Corte Suprema ordena retrotraer el caso con indicaciones específicas de no incluir una o varias pruebas en el nuevo juicio. El segundo ejemplo se refiere a casos en que la Corte declara una nulidad parcial, por ejemplo, cuando se declara la nulidad sobre uno de varios acusados o sobre uno de varios delitos imputados. Ambas situaciones son respaldadas en su texto con referencias a una cantidad importante de decisiones de Cortes de Apelaciones y de la propia Corte Suprema en nuestro país que no creo necesario repetir. ${ }^{68}$ Por ejemplo, la procedencia de nulidades parciales, es ya un criterio ampliamente asentado en las decisiones de la Corte Suprema. ${ }^{69} \mathrm{El}$ punto es que estos ejemplos dan cuenta que nuestro sistema jurídico en su funcionamiento habitual no opera con la lógica de privar por completo de todo efecto a los juicios anulados.

Se trata de una cuestión bastante lógica. Una interpretación extrema en la dirección opuesta haría inoperante varias otras reglas de nuestro sistema jurídico que funcionan sobre la base de reconocer la existencia de los juicios anulados. Tal vez si la más significativa en el área procesal penal es el artículo 387 inciso segundo del CPP que establece un límite a la procedencia del recurso de nulidad tratándose de dos sentencias condenatorias sucesivas. ${ }^{70}$ $\mathrm{Si}$ es cierto que el efecto del recurso de nulidad sería la inexistencia jurídica y fáctica del juicio y la sentencia anulada, ${ }^{71}$ a tal punto que esa sentencia no existe en el "mundo fáctico", jamás se podría dar lugar a la aplicación de esta norma ya que nunca podría considerarse y ni siquiera mencionarse la existencia del primer juicio y su sentencia debido al efecto de la nulidad. Se puede apreciar se trata de una interpretación que lleva al absurdo. Tanto así que nuestra Corte Suprema ha aplicado esta disposición en reiteradas ocasiones sin ningún problema desde este punto de vista. ${ }^{72}$ En el área penal sustantiva esta interpretación llevaría al absurdo de despenalizar al delito de falso testimonio contemplado en el artículo 206 del Código Penal en estos casos. En efecto, si un testigo o perito mintiere en contra del acusado en el juicio anulado, ${ }^{73}$ según esta doctrina esas declaraciones no podrían justificar la imposición de una pena ya que "no existirían". No me parece pueda tener razonabilidad alguna un argumento en esta dirección, lo que nuevamente da cuenta de los absurdos a los que lleva aplicar esta doctrina sin matices y distinciones.

\footnotetext{
${ }^{68}$ VIAL, "El derecho a confrontación", cit. nota no 4, p. 465-466.

${ }^{69}$ Complementado los casos citados por Vial con ejemplos más recientes de fallos de la Corte Suprema en la materia que dan cuenta que la posibilidad de decretar nulidades parciales es un criterio completamente asentado. Véase sentencias de la Corte Suprema en causa rol no 6613-2012 de 24 de octubre de 2012 y en causa rol no $1179-2013$ de 22 de abril de 2013.

${ }^{70} \mathrm{La}$ norma señala textualmente "Tampoco será susceptible de recurso alguno la sentencia que se dictare en el nuevo juicio que se realizare como consecuencia de la resolución que hubiere acogido el recurso de nulidad. No obstante, si la sentencia fuere condenatoria y la que se hubiere anulado hubiese sido absolutoria, procederá el recurso de nulidad en favor del acusado, conforme a las reglas generales."

${ }^{71}$ Es necesario recordar que el artículo 386 del CPP que la regla general de los efectos del recurso de nulidad es la de anular la "sentencia y el juicio oral".

${ }^{72}$ Entre otras véase sentencia de la Corte Suprema en causa rol n ${ }^{\circ}$ 6181-2007 de 18 de marzo de 2008. En este caso incluso la Corte debe pronunciarse por los contenidos de la primera sentencia de manera de mostrar que se estaba en presencia de una condena y que, por tanto, era aplicable el artículo 387 inciso segundo.

${ }^{73}$ Hipótesis en la que, vale la pena recordar, nuestra legislación establece la pena más alta en caso que se trate de un proceso por crimen o simple delito (presidio menor en su grado máximo), destacando así que se trata de la situación que representa un mayor disvalor jurídico-penal.
} 
DUCE, Mauricio. "El derecho a confrontación y uso de declaraciones emitidas en un juicio previo anulado".

En la misma dirección de entender que la nulidad del juicio y la sentencia no las hacen desaparecer del todo sino sólo para ciertos efectos jurídicos, se han pronunciado también otro sector de la doctrina a propósito de materias diferentes en las que este mismo debate tendría relevancia. ${ }^{74}$

En consecuencia, esta primera objeción constituye una interpretación que suprime un componente central del contrainterrogatorio y, por lo mismo, afecta injustificadamente el derecho a confrontación. Además, se trata de una argumentación que jurídicamente es bastante discutible y lleva a que, en caso de ser aplicada en diversos contextos, se produzcan soluciones absurdas para el funcionamiento del sistema procesal penal nacional.

\subsection{El órgano ante el cual fue prestada la declaración previa.}

Una segunda objeción que sería posible hacer al uso de las declaraciones del juicio previo anulado es que, aún superado el problema anterior, éstas no podrían ser utilizadas ya que el artículo 332 del CPP sólo autorizaría el uso de las mismas cuándo estas hubieren sido prestadas ante el fiscal, el abogado asistente del fiscal o ante el juez de garantía. En la mayoría de los casos al haber sido prestadas en juicio oral ordinario y no incluirse al tribunal oral en lo penal de manera específica en tal norma, no estaríamos frente a una declaración utilizable.

Una lectura del artículo 332 del CPP como la que he expresado también me parece errada. Por de pronto, es un tipo de argumento que no se hace cargo del problema de fondo que, como reiteradamente he señalado, se trata de un asunto de vigencia de garantías del debido proceso y, en particular, del ejercicio del derecho a confrontación en su dimensión de derecho a contrainterrogar. Más allá de eso, también presenta problemas de interpretación acerca del sentido y función general que cumple el artículo 332 del CPP en nuestro sistema. La omisión de mención al tribunal oral en lo penal no obedeció a una decisión explícita de nuestro legislador, sino simplemente a un defecto de redacción. Lo que ha querido el legislador al señalar a funcionarios específicos ante quienes se tienen que haber prestado las declaraciones previas ha sido el asegurar que, para que una declaración de este tipo pueda ser utilizada, ésta requiere haber sido prestada en condiciones que aseguren su confiabilidad. Es decir, condiciones mínimas que garanticen que efectivamente esa declaración correspondió al respectivo testigo o perito y que su contenido es el que fue formulado por el mismo. Esta idea queda clara cuando se estudia la historia de la ley. Así, la gran preocupación manifestada por nuestros legisladores en el Senado respecto a esta norma fue la de no incluir las declaraciones policiales por los riesgos que, debido a la falta de control, pudieran producirse en términos de establecer incentivos para la obtención forzada o bajo presión de las mismas. ${ }^{75}$

\footnotetext{
${ }^{74}$ BARRIENTOS, Ignacio, "La prohibición de reformatio in peius y la realización de nuevo juicio", Revista de Estudios de la Justicia n 9 (2007), pp. 175-207, pp. 198-199. En este caso dicha argumentación se realiza a propósito del análisis de los alcances de la regla de reformatio in peius contenida en el artículo 360 del CPP.

${ }^{75}$ En el segundo informe de la Comisión de Constitución, Legislación y Justicia del Senado se discutió ampliar la norma en estudio (en ese momento el artículo 369 del proyecto) incluyendo las declaraciones prestadas ante la policía Se señaló que "Discrepando de ese parecer, se apuntó que normalmente ante la policía se produce una presión sicológica sobre el imputado que afecta su libertad, y, se ha recogido información útil en estas declaraciones, debe incorporarse al juicio con la declaración de los funcionarios
} 
Polít. crim. Vol. 9, № 17 (Julio 2014), Art. 4, pp. 118-146.

[http://www.politicacriminal.cl/Vol_09/n_17/Vol9N17A4.pdf]

En este contexto, repito, la no inclusión de los tribunales orales en lo penal dentro de la norma en estudio obedeció a un error de redacción. En efecto, nadie podría dudar que una declaración prestada por un testigo o perito en un juicio oral ante un tribunal colegiado no ofrece garantías de confiabilidad. ${ }^{76}$ Igual cosa ocurre con el sistema de registro de dichas declaraciones, ya que al tratarse de un audio completo despeja cualquier duda acerca de los contenidos concretos expresados por el testigo o perito. De esta forma, no sería explicable que se permitiera el uso de declaraciones previas registradas en contextos de menor confiabilidad y registros de menor calidad (como pueden ser las prestadas ante el Ministerio Público sin la presencia del defensor y que no se transcriben de manera completa y literal) y en cambio se impida la posibilidad de ocupar las que debieran ser las declaraciones de mayor confiabilidad que el sistema puede tomar. En esta dirección se ha pronunciado también la Corte Suprema al señalar:

\begin{abstract}
"Si bien esta disposición no contempla las declaraciones prestadas en un juicio oral anterior, anulado, lo cierto es que tal realidad satisface el estándar impuesto por la norma en estudio, en cuanto se trata de declaraciones prestadas por el requerido ante la autoridad judicial, en el caso, no el juez de garantía que es el citado en el precepto, sino el tribunal de juicio oral en lo penal, con asistencia de todos los intervinientes convocados a la audiencia, esto es, con idénticas garantías de publicidad y bilateralidad., 77
\end{abstract}

En este contexto, el error de no incluir las declaraciones prestadas ante un tribunal oral en lo penal se produjo, en parte, por la poca comprensión del problema producto que cuando se diseñó y discutió nuestro CPP no se contaba con experiencia en regular instituciones para juicios de carácter acusatorio. De hecho, incluso en la fuente utilizada como base para la redacción de esta norma, proveniente de una tradición menos adversarial como la alemana, no se hace distinción sobre el tipo de órgano jurisdiccional en donde se ha tomado la declaración. En efecto, el parágrafo 253 de la Ordenanza Procesal Penal de Alemania no se hace distinción alguna, ni tampoco las hace la doctrina que se refiere al punto. ${ }^{78}$

Se suma a estos argumentos el hecho que dejar fuera declaraciones previas prestadas ante tribunales orales también produciría situaciones absurdas en nuestro sistema procesal penal. Por ejemplo, con una lectura literalista y formal del artículo 332 del CPP se permitiría utilizar este tipo de declaraciones cuando ellas fueron prestadas en juicios simplificados previos (ya que dicho procedimiento es llevado ante el juez de garantías), pero no cuando

policiales que la recibieron en calidad de testigos. La fuente de la prueba es la policía, y, si se fomenta la confesión como prueba, va a seguir existiendo el apremio ilegítimo." Véase Historia de la Ley 19.696, pág. 1477. (www.bcn.cl, última visita el 10 de enero de 2014).

${ }^{76}$ En esta misma dirección se ha resuelto un debate análogo en el sistema Italiano acerca de la extensión del uso de las declaraciones previas reguladas en el artículo 500.1 de su Código de Procedimiento Penal a las declaraciones prestadas en los incidentes probatorios (anticipos de prueba en nuestra terminología) no previstas explícitamente en la respectiva norma. Al respecto la doctrina de dicho país ha señalado que "...no hay ninguna razón lógica ni jurídica para excluir la posibilidad de confrontación justamente aquellas declaraciones que, por haber sido efectuadas durante el contradictorio ante el juez, ofrecen mayores garantías de confiabilidad". PLOTINO, El debate, cit. nota $\mathrm{n}^{\circ}$ 56, pp.135-136. Como se puede apreciar se trata de una situación muy similar en la que se resuelve el punto mirando el fondo del problema.

${ }^{77}$ Sentencia de la Corte Suprema en causa rol no 2866-2012 de 17 de junio de 2013, considerando vigésimo.

${ }^{78}$ Véase ROXIN, Derecho, cit. nota n ${ }^{\circ} 55$, p. 397. 
DUCE, Mauricio. "El derecho a confrontación y uso de declaraciones emitidas en un juicio previo anulado".

se tratara del procedimiento ordinario. Lo absurdo de esta solución salta a la vista. En el procedimiento ordinario el acusado normalmente arriesgará penas de mucho mayor entidad $\mathrm{y}$, por lo tanto, sus garantías del debido proceso debieran protegerse con más intensidad que en un procedimiento simplificado. La paradoja sería en este caso que el procedimiento simplificado otorgaría mejores protecciones al derecho a confrontar que el ordinario ya que permitiría el uso de las declaraciones del juicio previo anulado. Esto no tiene explicación lógica con una interpretación del artículo 332 del CPP que ponga un puro acento en la lectura formal de la regla.

En consecuencia, no me parece que esta segunda objeción pueda constituir un obstáculo serio para impedir el uso de las declaraciones previas prestadas ante el tribunal oral en lo penal en el juicio que ha sido anulado. Ello tanto por las razones vinculadas al ejercicio de las garantías individuales como de la correcta interpretación que debiera hacerse del artículo 332 del CPP.

\subsection{La prohibición del artículo 334 inciso segundo del CPP.}

Un último argumento que se puede invocar en contra de la interpretación que he sostenido dice relación con la regla contenida en el artículo 334 inciso segundo del CPP. En ella se establece una prohibición de incorporar como medio de prueba o dar lectura a actas o documentos que dieren cuenta de actuaciones o diligencias declaradas nulas. ${ }^{79}$ Así, entonces, se podría sostener que las declaraciones prestadas en el juicio previo, al haber sido anulado, caerían dentro de la regla prevista en esta norma y su uso estaría prohibido.

Se trata de un argumento que no me parece recoge el sentido y función que cumple la prohibición del artículo 334 del CPP, por lo que no debiera ser considerado. El artículo 334 contiene una norma general de prohibición de uso de cierto material cuando se pretende usarlo como medio de prueba (sustantiva o sobre el fondo). Como dice Moreno:

"La prohibición consagrada en el artículo 334 de nuestro ordenamiento procesal penal está referida a invocar como medios de prueba aquellos documentos y registros dirigidos a probar el hecho punible y la participación culpable del imputado, pero no aplicaría la prohibición cuando el debate se circunscribe a la credibilidad del medio de prueba que se está utilizando para acreditar el hecho punible o la participación."

La explicación de esto se encuentra en la idea que el diseño del artículo 334 estuvo fuertemente centrado en el objetivo de disponer de una regla que impidiera el fenómeno de sustitución de la declaración de testigos en la audiencia (por ejemplo los policías) por medio de la lectura de actas policiales como había sido común en América Latina. La regla fuerte de prohibición se diseñó entonces como una regla de exclusión de prueba sobre el fondo del asunto de manera de preservar así la centralidad del juicio oral. ${ }^{81}$ Como contrapartida, se trata de una regla que no ha pretendido regular casos como el artículo 332

\footnotetext{
${ }^{79}$ El texto literal señala "Ni aún en los casos señalados se podrá incorporar como medio de prueba o dar lectura a actas o documentos que dieren cuenta de actuaciones o diligencias declaradas nulas, o en cuya obtención se hubieren vulnerado garantías fundamentales"

${ }^{80}$ MORENO, “Algunas consideraciones", cit. nota n 27, p. 200.

${ }^{81}$ En este mismo sentido se pronuncia HORVITZ/LÓPEZ, Derecho tomo II, cit. nota no 29, p. 318.
} 
Polít. crim. Vol. 9, № 17 (Julio 2014), Art. 4, pp. 118-146.

[http://www.politicacriminal.cl/Vol_09/n_17/Vol9N17A4.pdf]

o como el artículo 336 inciso primero (prueba sobre prueba) que establecen la posibilidad de utilizar estas actas no para probar el fondo del asunto sino aportar elementos para pesar la credibilidad de la prueba de fondo.

Aún cuando no se considerare este punto, habría otra vía argumentativa para limitar severamente los alcances de esta objeción: entender que la prohibición de uso sólo afectaría a los elementos que sirvieron de motivo de invalidación del juicio y no a todos los actos o diligencias realizados en el mismo. Se trata del camino argumentativo seguido por la Corte Suprema en su decisión de junio de 2013. En ella la Corte sostuvo:

\begin{abstract}
"En efecto, del tenor de la norma citada aparece que tal prohibición afecta a los elementos que sirvieron de motivo a la invalidación, los que no podrían ser usados en un caso como el que se plantea en autos, desde que aquellos probablemente habrán de ser excluidos del nuevo juicio, precisamente por la sanción de nulidad o la infracción de garantías constitucionales. Sin embargo, si la invocación se hace a otros elementos de un juicio anulado, que no han sido las piezas que motivaron la invalidación, no se advierte cómo podría tal elemento caer en la prohibición del artículo 334 en análisis" ${ }^{\prime \prime 2}$
\end{abstract}

Como se puede observar, en esta segunda línea se impide la posibilidad de argumentar en forma genérica la regla del artículo 334 inciso segundo. Ella sólo podría ser invocada como una razón para impedir el uso de la declaración previa en los casos en los cuáles dicha declaración hubiere sido el motivo de la nulidad del juicio. Como muy bien dice la Corte Suprema, eso sería bastante excepcional ya que lo normal en una hipótesis de ese tipo sería el excluir del todo la declaración que dio origen a la nulidad con lo cual en el nuevo juicio no se daría el escenario de una declaración susceptible de ser contrastada por medio del uso del artículo 332 del CPP.

En conclusión, cualquiera de estos dos caminos argumentativos hace perder fuerza a la objeción en análisis, la que en el mejor de los casos sólo podría operar como un límite al uso de las declaraciones previas en casos muy excepcionales o casi de laboratorio. Por lo mismo, no parece tratarse de un obstáculo serio para entender que nuestro sistema procesal penal admite el uso de las declaraciones del juicio prestadas en el anulado para los efectos del artículo 332 del CPP.

\title{
Conclusiones
}

Como he visto en forma precedente, situar el uso de las declaraciones previas para efectos del artículo 332 del CPP como una herramienta clave para permitir el ejercicio pleno y efectivo del derecho a contraexaminar tiene una enorme relevancia para resolver el problema que ha planteado este trabajo. La negativa al uso de una declaración previa proveniente de un juicio anulado hace que se comprometa, para el acusado, el ejercicio de un derecho fundamental si es que en el nuevo juicio efectivamente un testigo o perito presenta una declaración inconsistente o con contradicciones respecto a su declaración en el juicio previo. Ello impone contar con razones fuertes para justificar una decisión de ese

\footnotetext{
${ }^{82}$ Sentencia de la Corte Suprema en causa rol n n $^{2866-2012 ~ d e ~} 17$ de junio de 2013, considerando vigésimo.
} 
DUCE, Mauricio. "El derecho a confrontación y uso de declaraciones emitidas en un juicio previo anulado".

tipo, las que no parecieran existir en nuestra legislación. En efecto, el legislador nacional no ha manifestado de una manera explícita y clara su voluntad de prohibir el uso de estas declaraciones en la hipótesis en análisis. Esto me permite afirmar que las razones que se han esgrimido usualmente en tribunales para negar su procedencia no tengan un fundamento sólido y razonable. Se trata de argumentos que parecen obedecer a debates doctrinales muy abstractos y que no consideran los valores en juego o que se basan en una lectura formalista y parcial de las reglas que conforman nuestro sistema procesal penal. Si bien hay que reconocer que el CPP sería perfectible en esta materia, sus reglas actuales no impiden que una interpretación que, considerando las garantías fundamentales reguladas en los tratados internacionales, la Constitución y el propio CPP, permita un uso amplio de las declaraciones previas.

La decisión de la Corte Suprema de junio de 2013 constituye un avance muy importante en esta dirección. En ella efectivamente se reconoce la dimensión de protección del ejercicio de un derecho fundamental que hay detrás del uso del mecanismo del artículo 332 del CPP cuando es el acusado quien lo invoca. Es de esperar que ella, con ayuda de los argumentos $\mathrm{y}$ antecedentes contenidos este trabajo, sirva para consolidar una práctica jurisprudencial uniforme en la materia. 
Polít. crim. Vol. 9, № 17 (Julio 2014), Art. 4, pp. 118-146.

[http://www.politicacriminal.cl/Vol_09/n_17/Vol9N17A4.pdf]

\section{REFERENCIAS BIBLIOGRÁFICAS}

\section{1.- Libros:}

BAYTELMAN, Andrés; DUCE, Mauricio, Litigación Penal Juicio Oral y Prueba, Santiago: Ediciones Universidad Diego Portales, 2005.

BLANCO, Rafael; DECAP; Mauricio, MORENO; Leonardo; ROJAS, Hugo, Litigación estratégica en el nuevo proceso penal, Santiago: LexisNexis, 2005.

BOTERO, Martín, El sistema procesal penal acusatorio: funcionamiento y estructura prospectiva de Italia para América Latina, Bogotá: Ediciones Jurídicas Andrés Morales, 2008

CHAHUÁN, Sabas, Manual de nuevo procedimiento penal, Santiago: LexisNexis, 2006.

CHIESA, Ernesto, Derecho procesal penal de Puerto Rico y Estados Unidos vol. I, Puerto Rico: Editorial Forum, 1995.

, Derecho procesal penal de Puerto Rico y Estados Unidos vol. III, Puerto Rico: Editorial Forum, 1995.

COUSO, Jaime; MERA, Jorge, Precedentes y justicia penal, Santiago: Ediciones Universidad Diego Portales, 2011.

DECASTRO, Alejandro, El contrainterrogatorio, Colombia: Librería Jurídica Comlibros, 2005.

DRESSLER, Joshua Dressler; MICHAELS, Alan, Understanding criminal procedure, New York: LexisNexis, 2006.

FONTHAM, Michael, Trial technique and evidence, Estados Unidos: National Institute for Trial Advocacy, 2008.

GIANELLI, Paul, Understanding Evidence, Estados Unidos: LexisNexis, 2006.

GÓMEZ COLOMER, Juan Luis, El proceso penal alemán: introducción y normas básicas, Barcelona: BOSCH, 1985.

HORVITZ, María Inés; LÓPEZ, Julián, Derecho procesal penal Chileno tomo I, Santiago: Editorial Jurídica de Chile, 2002. 2004.

JIMÉNEZ, Rolando, Prontuario de derecho probatorio puertorriqueño, Puerto Rico: Ediciones Situm, 2010.

LORENZO, Leticia, Manual de litigación, Buenos Aires: Ediciones Didot, 2012.

MATURANA, Cristián; MONTERO, Raúl, Derecho procesal penal tomo II, Santiago: AbeledoPerrot, 2010.

McGOLDRICK, Dominic, The Human Rights Committee, Oxford. Clarendon Press, 1996.

NOWAK, Manfred, U.N Covenant on Civil and Political Rights CCPR Commentary, Germany: N.P Engel Publisher, 2005.

ORTEGA, Waldo, Litigación oral para el proceso penal, Santiago: Ril Editores, 2012.

OVEY, Claire; WHITE, Robin, The European Convention on Human Rights, Oxford: Oxford University Press, 2006.

PARK, Roger; LEONARD, David; GOLDBERG, Steven, Evidence law, St. Paul (Estados Unidos): Thomson West, 2004.

PLOTINO, Francesco, El debate en el nuevo Código de Procedimiento Penal, Córdoba (Argentina): Editorial Mediterránea, 2001. 
DUCE, Mauricio. "El derecho a confrontación y uso de declaraciones emitidas en un juicio previo anulado".

ROXIN, Claus, Derecho procesal penal, Buenos Aires: Editores del Puerto, 2000.

SUMMERS, Sarah, Fair trials: The European criminal procedural tradition and the European court on human rights, Oxford: Hart Publishing, 2007.

TORO, Constanza, El debido proceso penal, Santiago: Ediciones Jurídicas de Santiago, 2009.

TORO, Ibed, El derecho al debido proceso, Santiago: El Jurista Ediciones Jurídicas, 2012.

TRECHSEL, Stefan, Human rights in criminal proceedings, New York: Oxford University Press, 2006.

VAN DIJK, Pieter; VAN HOOF, Fried; VAN RIJN, Arjen; ZWAAK, Leo (eds.), Teoría y práctica del convenio europeo de derechos humanos, Colombia: Universidad Los Andes, 2009.

VIAL, Pelayo, Técnicas y fundamentos del contraexamen en el proceso penal chileno, Santiago: Librotecnia, 2006.

\section{2.- Artículos en revistas y capítulos de libros:}

BARRIENTOS, Ignacio, "La prohibición de reformatio in peius y la realización de nuevo juicio", Revista de Estudios de la Justicia no 9 (2007), pp. 175-207.

BAYTELMAN, Andrés, "El juicio oral", en: VV.AA, Nuevo Proceso Penal, Santiago: Editorial Jurídica Conosur, 2000, pp. 227-282.

DUCE, Mauricio; MARIN, Felipe; RIEGO, Cristián, "Reformas a los procesos civiles orales: consideraciones desde el debido proceso y la calidad de la información", en: VV.AA, Justicia Civil: Perspectivas para una Reforma en América Latina, Santiago: Centro de Estudios de Justicia de las Américas, 2008, pp. 13-94.

FUENTES, Claudio, "Límites a la vigencia del principio contradictorio en los juicios de familia", Revista de Derecho Universidad Católica de la Santísima Concepción no 21 (2010), pp.49-63.

HERMOSILLA; Francisco, “¿Cuáles son las Excepciones a la práctica de la prueba en juicio oral?", en: MIRANDA, Manuel; CERDA, Rodrigo; HERMOSILLA, Francisco. Práctica de la prueba en el juicio oral, Santiago: Librotecnia, 2012, pp. 183-196.

MORENO, Leonardo, "Algunas consideraciones sobre el funcionamiento de la reforma procesal penal”, en: DECAP, Mauricio; DUCE, Mauricio; MORENO, Leonardo; SÁEZ, Jorge, El modelo adversarial en Chile, Santiago: Thomson Reuters, 2013, pp. 67-218.

ROJAS, Julio, "El rol del juez en la prueba: efectos que genera en el juicio oral la formulación de preguntas aclaratorias a testigos y peritos conforme al artículo 329 inciso cuarto del Código Procesal Penal," en: VV.AA, Diez años de la reforma procesal penal en Chile, Santiago: Ediciones Universidad Diego Portales, 2011, pp. 432-456.

VIAL, Pelayo, "El derecho a confrontación con declaraciones de un juicio anulado en el marco del proceso penal", Polít. crim. Vol. 6, № 12 (diciembre 2011). Art. 6, pp. 448-473, en: www.politicacriminal.cl/Vol_06/n_12/Vol6N12A6.pdf (última visita el 6 de enero de 2014). 
Polít. crim. Vol. 9, № 17 (Julio 2014), Art. 4, pp. 118-146.

[http://www.politicacriminal.cl/Vol_09/n_17/Vol9N17A4.pdf]

\section{3.- Jurisprudencia}

3.1.- Nacional:

Sentencia de la Corte Suprema en causa rol no 2345-2005 de 13 de julio de 2005.

Sentencia de la Corte Suprema en causa rol no 3795-2006 de 26 de septiembre de 2006.

Sentencia de la Corte Suprema en causa rol no 5417-2007 de 24 de diciembre de 2007.

Sentencia de la Corte Suprema en causa rol no 6181-2007 de 18 de marzo de 2008.

Sentencia de la Corte Suprema en causa rol no $5116-2012$ de 5 de septiembre de 2012.

Sentencia de la Corte Suprema en causa rol no 6613-2012 de 24 de octubre de 2012.

Sentencia de la Corte Suprema en causa rol no 1179-2013 de 22 de abril de 2013.

Sentencia de la Corte Suprema en causa rol nº 286-2012 de 17 de junio de 2013.

\section{2.- Internacional:}

Sentencia de la Corte Europea de Derechos Humanos de 10 de febrero de 2006 caso BocosCuesta v. The Netherlands.

Sentencia de la Corte Interamericana de Derechos Humanos de 22 de noviembre de 2005, caso Palamara vs. Chile. 